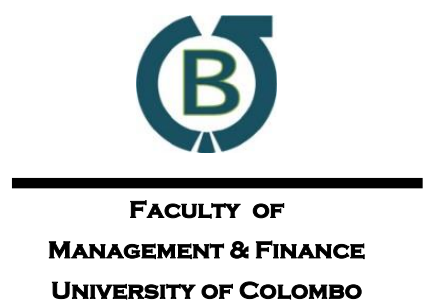

Colombo

Business

Journal

UNIVERSITY OF COLOMBO

INTERNATIONAL JOURNAL OF

THEORY \& PRACTICE

Vol. 10, No. 02, December, 2019

\title{
Market Microstructure Noise, Intraday Stock Market Returns, and Adaptive Learning: Indian Evidence
}

\author{
Paritosh Chandra Sinha四 \\ Rabindra Mahavidyalaya, Hooghly, W.B., India
}

\begin{abstract}
What drives intraday traders' sentiments in the stock markets: information or noise? This paper argues that the market microstructure noise (MMN) manifests intraday traders' aggregate sentiments depicted by chaotic and noisy market returns. It examines if intraday stock market returns, returns' variances and higher order moments are erratic, noisy and nonnormal. It shows that the intraday Bombay Stock Exchange (BSE) Sensex and National Stock Exchange (NSE) Nifty index returns approximate to zero-mean, zero-variance but skewed and leptokurtic in distributions. In exploring the intraday market index returns, standardisation process reveals noises in the BSE market, but it is evened up in the NSE market. Since intraday traders' market sentiments and decision choices are behavioural, noisy but adaptive, their decision choices need strategies given that those strategies have numerical "attractions" that determine choice probabilities. We explore the adaptive Experience Weighted Attraction (EWA) learning parameters to show persistent MMN in intraday traders' adaptive learning behaviours.
\end{abstract}

Keywords: Adaptive Learning Behaviours Approach, Behavioural Financial Economics, Market Microstructure Noise, Non-Normality of Stock Market Returns

Received:

12 July 2019
Accepted revised version:

30 October 2019
Published:

31 December 2019

Suggested citation: Sinha, P. C. (2019). Market microstructure noise, intraday stock market returns, and adaptive learning: Indian evidence. Colombo Business Journal. (10)2, 25-74

DOI: http://doi.org/10.4038/cbj.v10i2.50

(C) 2019 The Authors. This work is licenced under a Creative Commons Attribution 4.0 International Licence which permits unrestricted use, distribution, and reproduction in any medium, provided the original work is properly cited.

$\bowtie$ paritoshchandrasinha@gmail.com: iD https://orcid.org/0000-0003-0513-6700 


\section{Introduction}

In a trading day at no new news, the ordered Electrocardiogram (ECG) reports of the traders (fully rational, conscience and mentally sound) rarely match the intraday price-charts of any active stock in our known stock markets. The mismatch is so profound that, researchers may get a 'psychological impression' about intraday traders that they are neither rational nor conscience, but either irrational or unsound or both. Behaviour wise, intraday traders tend to be normal human beings who update their past actions at the presence of new information. The heart creates impulses, minds apply both intuitions and memory, emotions make colourful images of success or failures, while sensory organs are keen to accumulate new news. We even personify stocks with human qualities and always make their psychological report cards. At bull or bear personas, these normal human beings - the intraday traders are subject to greed or fear, desire or distress, love or hates, happiness or despairs, likes or dislikes etc. These make the presence of stock markets as a living entity in the markets (Jaffe, 2010; Summa, 2004).

Now, what does the above-mentioned human-like 'normal' (not rational) phenomena for stocks' intraday trading prices across the stock markets mean to us? Shiller (2015) has called this as the "irrational exuberance". He has found that structural, cultural and psychological factors contribute to irrational exuberance. Since economists always pursuit their search for rationality behind irrational phenomena, they do believe even in transforming irrational patterns into rational patterns. This leads them towards exploring the chaos theory of mathematics in explaining the dynamics of "chaos and order in the capital markets" (Trippi, Chorafas, \& Sekiguchi, 1994; Peters, 1996) and that of "a fractal view of financial turbulence" (Peters, 1994; Mandelbrot \& Hudson, 2007). Hence, the chaos theory in financial economics tries to explain misbehaviour of traders in dynamic pricing in financial markets.

Proponents of the chaos theory of capital markets provide more proposals than proofs. In explaining the misbehaviour, a pleasant first step by researchers is to explore the experiential query of 'irrational exuberance' with a candidate stock's intraday trading prices. But, reviewing the ECG report of one 'human' person is not sufficient to replicate the same for others. Let us explore the 'irrational exuberance' with reference to the intraday index movements of two leading stock markets in India. The complex next step, however, rests in exploring the chaos in capital markets that is, the fractal behaviour of the misbehaviour. Since the chaos represents effects of long memory and additive property of human learning behaviour, in pursuit to the 
second step, this study explores the adaptive learning behaviour criteria in Camerer and Ho (1999). Both steps if coined together can be marked as "market microstructure noise" in the neoclassical finance literature (Martin, 2012; Chin \& Lee, 2018). The former step explores the 'inner chaos' of intraday traders while the latter one goes with their 'outer chaos' at stock markets.

In exploring the chaos, this study contributes to our knowledge on the capital market with the behavioural finance approach rather than the neoclassical one. Stock market indices are assumed to incorporate an aggregate chaos, the market microstructure noise. It methodologically shows that chaos, aggregate marketsentiment representing traders' impulse at bull-market or bear-market rallies or sector-specific depressions etc., can be framed into traders' adaptation to the changes in market microstructure noise (henceforth MMN). It contributes to the empirical literature in exploring if stock markets perform as argued by rational finance theorists that returns are normal in distributions and if investors' long memory to market returns shows the behavioural additive property of the adaptive experience-weighted attraction (EWA) learning criteria in Camerer and Ho (1999). The study limits its scope of explorations into two basic research queries, that is whether the intraday stock market returns depicting aggregate sentiments in the NSE Nifty and the BSE Sensex are normal in distributions or not and whether investors' decision choices in the terms of said returns could be explained by the EWA learning criteria or not.

The rest of the paper is organised as follows: The next section reviews the literature briefly, followed by a section on the methodology of the study. Then empirical findings are presented with discussions. The final section of the paper presents key conclusions along with suggestions for future research and practical implications of the findings.

\section{Literature Review}

The phrase market microstructure noise (MMN) is new in financial economics. It is used contrarily in the standard finance and behavioural finance studies. In standard finance, it shows the presence of systematic noise in market-microstructure models and it explains pricing dynamics in financial markets. It is realised when exploring random and non-random error components and thereby, modelling the prices, returns and noises. At presence of market efficiency, it discusses the role of limits to arbitrage in pricing dynamics (Kyle, 1985; Att-Sahalia1 \& Yu, 2009; Diebold \& Strasser, 2008; Hansen \& Lunde, 2006). "Given the vast diversity in potential models, sampling frequencies, levels of microstructure noise, realized 
variation estimators and forecasting schemes" (Andersen, Bollerslev, \& Meddahi, 2011; p. 231), the studies on MMN in the standard finance are limited. Andersen, Cebiroglu, and Hautsch, (2017) have showed that different time-varying market environments have fundamental regimes of positive (negative) serial correlations and these induce price momentum (price reversal) in observed returns. Sinha (2016b) has showed that stocks' returns could be explained up to $50 \%$ at the Adj. $\mathrm{R}^{2}$-value with the known information variables.

In sharp contrast, MMN includes a batch of research agenda in behavioural finance. In Sinha (2015a), MMN is generalised under a heading of "traders' psychology... and preferences" (pp. 800-805). Psychological bias includes ambiguity aversion, illusion of control, over-confidence, elicited belief and myopic loss aversion (Sinha, 2018). It also brings traders' over reaction and price reversal expectations (Fung, Lam, \& Lam, 2010; p. 429-430). It represents traders' psychological biases contributing to correlated trading by individuals (Barber, Odean, \& Zhu, 2009). De Long, Shleifer, Summers, and Waldmann (1990) have showed that unpredictable nature of beliefs by noise traders about stock market bubbles, arbitrageurs' risk aversion and short-horizon contribute to formation and continuation of noise trading and presence of market sentiments.

Now, noise trading and microstructure noise exist at the presence of heterogeneities in markets. For example, information heterogeneity divides traders into arbitrageurs, short sellers and noise traders (Bloomfield, O'Hara, \& Saar, 2009). Heterogeneity exists at expectations of traders as well (Boswijk, Hommes, \& Manzan, 2007). Expectation heterogeneity arises at information context (Yalamova \& McKelvey, 2011), investment-horizon context (Subbotin, 2010), investors' belief context (He, 2012), and traders' behavioural context (Pan, Shi, Wu, \& Zhang, 2015). Hence, heterogeneous beliefs, biases, preferences and expectations induce effective market microstructure noise.

Nonetheless, investors' heterogeneous beliefs matter in asset pricing (Anderson, Ghysels, \& Juergens, 2005). Gandhi and Serrano-Padial (2015) have showed that differences in beliefs of agents lead to systematic pricing pattern of long-short bias while noise traders exhibit belief dispersion. Kasa, Walker, and Whiteman (2013) have showed that when there are heterogeneous beliefs, competitive traders with idiosyncratic noise about the fundamentals remain asymmetrically informed with regard to the equilibrium while asset prices exhibit violations of variance bounds, predictability of excess returns, and rejections of cross-equation restrictions. In addition, heterogeneity in behavioural biases induces significant price reversals even 
with loss-averse traders. In Coval and Shumway (2005), behavioural biases show significantly fast price reversal among the Chicago Board of Trade proprietary traders than those of unbiased traders. Heterogeneous information also sets the environment for biased trading (Wolfers \& Zitzewitz, 2004) while traders' heterogeneous expectation about the uncertain future becomes its driving force (Tziralis \& Tatsiopoulos, 2007). In an experimental setting, Sinha (2018) has showed that informed (noise) traders exhibit greater exposure of ambiguity aversion (biases of illusion of control, elicited belief and myopic loss aversion) than those of noise (informed) traders. In an experimental STOCCER championship market, Luckner et al. (2011) have found that nationality of traders also influences their rational decision choices even in hypothetical experimental markets.

But what makes the market microstructure noise so attractive in the stock markets? Investor sentiments (in the Indian cricket team in one-day international cricket matches) can be considered as ideal predictors of returns, realised volatility and jumps in the intraday trading in Indian stock markets (Gkillas, Gupta, Lau, \& Suleman, 2019). Rao and Srivastava (2012) have showed that traders' sentiments in Twitter discussions greatly affect movements of stocks prices and market indices of the Dow Jones Industrial Average Index (DJIA) and National Association of Securities Dealers Automated Quotations (NASDAQ) - 100 in the U.S. Traders' sentiments also go viral on the Sina Weibo, a Twitter's variant in China (Xu, Liu, Zhao \& Su, 2017). A 'viral' implies the presence of relative market sentiments viz., anger, disgust, fear, joy, and sadness. Market sentiments are asymmetric and skewed towards the two extreme sentiments of bear and bull (Moseki, Rao, \& McMillan, 2017). Hence, market sentiments are linked to non-normality of movements of stock prices and market indices. Interested readers are referred to the review of market sentiments at internet big data exposure in $\mathrm{Ye}$ and $\mathrm{Li}$ (2017).

Furthermore, investors' aggregate sentiment has clearly discernible, important and regular effects on individual firms and stock markets as well (Baker \& Wurgler, 2007). Baker and Wurgler (2007) have showed that prices of stocks which are difficult to arbitrage are mostly affected by investors' aggregate sentiments. The aggregate sentiments involve herding behaviour, which refers to an attitude that tend to believe more on others' information rather than that on one's own information (De long et al., 1990) and going against the herd by informed arbitrageurs is costly and risky as well (Shleifer \& Vishny, 1997). Again, Kumari and Mahakud (2016) have found a unidirectional causality from sentiment to the stock market volatility. Tuyon, Ahmad, and Matahir (2016) also have revealed that investor sentiment has significant effects on the short run and long run stock market returns in the Malaysian stock 
market and the effects are heterogeneous across firm sizes, industry groups and market states etc. Simply, investors' aggregate sentiment in the markets results in the market microstructure noise.

But, how do researchers correlate sentiment effects beyond the task of modelling? At the lower-quantiles of conditional distributions of realised volatility and jumps in the market index, Gkillas et al. (2019) have showed that loss of Indian cricket team has higher predictability than its win when explaining returns, realised volatility and jumps in the intraday trading in Indian stock markets. With the empirical high frequency trading data of stocks listed in the Oslo Stock Market in Norway, Dinh (2017) has found that idiosyncratic risk has more robust influence than systematic risk in asset pricing, while liquidity has a higher significant effect on idiosyncratic risk than systematic risk. Besides, with intra-day one-minute trading data of the NSE Nifty and BSE Sensex listed firms in India, Sinha (2015b) has empirically explored the nature and magnitudes of noise traders' risk in India. The study has showed that the systematic and firm-specific noise components of the both returns and risks include both the idiosyncratic and systematic aspects. With the high frequency trading data of the selected scripts, Sinha (2016a) further has showed that investors in the said two leading Indian stock markets depict crowds of positive and negative herding significantly and there is huge noise in the equilibrium pricing system. Kumari and Mahakud (2015) have also demonstrated that, institutional investors act on optimism and herding attitudes in India. These behavioural sentiments contribute noises, and these are priced as the systematic risk factor in stock markets.

\section{Research Methodology}

In exploring the stated basic research queries, the study primarily presents its empirical framework on the distributional properties of stock market returns and their higher order moments. It manifests that if the MMN depicts market sentiments, then market returns and their higher order moments should depict uncertainty leading the distributions to be non-normal. Hence, we explore the econometric foundations of non-normality to stock market returns and then, we track the investors' adaptive experience-weighted attraction (EWA) learning behaviour.

\section{Econometric Foundations to Non-Normality}

In an early study on the Random Walk Hypothesis for the stocks' price changes, Fama (1965) has demonstrated that the distribution of price changes of the United States (US) stock markets are with larger tails and steeper central portion (p.52) and these are neither normal nor even approximately normal (p.55-56). Fama (1965) has 
showed that the said non-normality is caused neither by the mix of many normal distributions of same mean and different variances nor by the non-stationarity of empirical data. Fama (1965) has showed that stocks' returns follow Mandelbrot (1962) hypothesis ${ }^{1}$. Mandelbrot (1965) hypothesises that the empirical data of price changes follow the stable Paretian distribution ${ }^{2}$ with their characteristic exponents of kurtosis $(\alpha)$ being less than 2 where $\alpha$ is a measure of the height of extreme tail areas of the distribution. Mandelbrot (1962) and (1965), however, have not clarified if the lower limit of $\alpha<2$ included the negative Kurtosis values.

In review of Fama (1965) and other similar studies, Elton, Gruber, and Kleindorfer (1975) have showed that “...if the log of price relatives follows a stable distribution, then neither price relatives nor returns follow a stable distribution" (p. 234). That is, neither price-proportions nor absolute returns follow a systematic distribution. Furthermore, the standard finance theory and related empirical test design are based on the assumption that the returns follow non-normal stable distribution. Therefore, both become erratic and inconsistent with the empirical data of $\log$ of investment relatives (Elton, et., al., 1975; p. 231). They have showed that "for the distribution of price relatives to have positive absolute moments, the price relatives must either be normal or follow a non-normal stable distribution with $\beta=$ -1 " where $\beta$ is the measure of skewness (p. 234). They have concluded that if the log of price relatives follows a non-normal stable Paretian distribution, then the mean or the higher moments of the returns i.e., price-proportions or absolute returns do not exist. In exploring such uncertainty, this study examines whether market returns (as derived by using the Log of Index Relatives) and their higher order moments follow the normal distribution or not.

Given the methodological complexity, we follow Fama (1965) in defining stock market returns. Ardliansyah (2012) has found that the measure of skewness, $\beta$ may have higher and lower (than -1) negative values empirically for different markets. Negative skewness illustrates that investors are exposed to few extreme losses but frequent small gains. Ghose and Koner (1995) argue that the stable Paretian

\footnotetext{
1 The Mandelbrot (1962) hypothesis suggests that the most important feature of the distribution of stocks' returns should be the length of their tails. That is, the extreme tail areas should contain more relative frequency than would be expected if the distributions were normal.

${ }^{2}$ Stable Paretian distributions have four parameters: (i) location parameter, $\delta$; (ii) a scale parameter $\gamma$; (iii) an index of skewness, $\sigma$; and (iv) a measure of the height of the extreme tail areas of the distribution, called the characteristic exponent, $\alpha$. For details of the derivation of the distribution, readers are referred to Appendix in Fama (1965; p. 101).
} 
distribution is consistent with the Generalised Autoregressive and Heteroskedastic models (GARCH), where fat-tailed (long-tailed) distributions of returns are caused by temporal clustering (long-memory) of the volatility component (p.225). Researchers extend the stable Paretian distribution in developing conditional GARCH models (McCulloch, 1996; Garcia, Renault, \& Veredas, 2011), but little work is done in the behavioural finance front with investors' adaptive learning behaviours.

\section{Empirical Understandings}

Before jumping on the empirical part of our study, we briefly explore the existing empirical understandings in international and Indian contexts. These assist us in developing the methodology, particularly in choice of the variables, parameters, and methods as well.

With the marginal and joint moments of asset returns of the 30 US Dow Jones Industrial Average (DJIA) data, Richardson and Smith (1993) have empirically showed that the multivariate normal assumption cannot be justified for stock returns and market-model residuals in both their marginal and joint distributions. The daily stock market returns of the European security markets (Aparicio \& Estrada, 2001), returns' volatility in the DJIA, The Standard and Poor (S\&P) 500, and Center for Research in Security Prices (CRSP) data (Kim \& Kon, 1994) and the other higher order co-moments with the CRSP data (Chung, Johnson, \& Schill, 2006) of returns are distributed non-normally. With data of high-frequency intraday transaction prices on individual stocks listed in the DJIA, Andersen, Bollerslev, Diebold, and Ebens, (2001) have found that the unconditional distributions of realized variances and covariances of stock returns are highly right-skewed. With the Korean Stock Market data, Yoon and Kang (2008) have showed non normality and non-linear dynamics of stock returns characterized by long memory properties and market business cycles. With the CRSP and Compustat firms, Chung, et. al., (2006) have further found evidence that normality is rejected for returns for daily, weekly, monthly, quarterly, and semi-annual intervals. They have showed that the sample firms' skewness increases with the return interval while their heights are somewhat leptokurtic. Garcia et al. (2011) have explored the stable distributions of the S\&P 500 Index returns over five-minute intervals and have found that the index displays fat tails which are inconsistent with normal distributions. In a recent study, Joseph, Turner, and Jeremiah (2016) have empirically showed that economic and financial time series data are time varying and non-Gaussian with smooth, compactly supported, and band limited power spectral density estimates. 
The related Indian studies only explore weak-form as opposed to semi-strongform of market efficiency. Poshakwale (1996) finds distribution of stocks' prices in the BSE non-normal during 1987-94 rather positively skewed with a kurtosis value of -0.530 . He has not explored if the negative Kurtosis data follows stable Paretian distribution or if the negative (positive) value for the skewness measure is consistent with a positive (negative) value for the kurtosis measure for the return distribution. Gupta and Yang (2011) show that during 1997-2011, the daily returns of the NSE and BSE are respectively negatively and positively skewed with the kurtosis value of 9.72 and 8.74. There is an urgent need for research on the intraday one-minute stock market index data based on the Indian context.

\section{Intraday Stock Market Returns, Higher Order Moments and MMN}

The study now puts forth the empirical framework for distributional properties of market returns and their higher order moments as well. The same is followed by the framework for the adaptive Experience Weighted Attraction (EWA) learning model. Here, we describe the intraday trading data, define the variables for market returns and the higher order moments, sketch the adaptive learning criteria for decision choices, identify the EWA learning model for MMN, and define the EWA variables and generate their data.

\section{Data Descriptions}

The study uses 1D timestamp intraday trading data for the NSE Nifty Open Index and that for the BSE Sensex Open Index. The data cover 81 trading days out of the trading months of July 2016 (13 days), August 2016 (21 days), September 2016 (18 days), October 2016 (6 days), November 2016 (3 days), December2016 (14 days), January 2017 (4 days), February 2017 (0 days) and - March 2017 (2 days). In an overall of 81 days, the population data so used have 31166 (26261) timestamp 1D index data for the NSE-Nifty (BSE-Sensex) Open Index. On an average, the population have 384 (324) timestamp 1D data a day for the NSE Nifty-Fifty (BSE Sensex) index.

\section{Variable Definitions}

The study uses Fama's (1965) definition for the return variable - Log of Index Relatives, $\mathrm{LIR}_{\mathrm{t}}$. The variable Log of Index Relative, $\mathrm{LIR}_{\mathrm{t}}$ is defined as $\mathrm{Ln}\left(\mathrm{OI}_{\mathrm{t}} / \mathrm{OI}_{\mathrm{t}-1}\right)$, $\mathrm{OI}_{t}$ stands for Opening Index 1D data at time $t$. This log-transformed data serve proxy for the price or investment data in generating the market return variables and their higher order moments. Following the critics of Elton, et., al. (1975), the return variable is defined in four alternative methods. The other three variable definitions are Mean Return of Log Index Relatives (MR_LIR ${ }_{\mathrm{t}}$, Standardized Return of Log 
Relatives $\left(\mathrm{SR}_{\mathrm{L}} \mathrm{LIR}_{\mathrm{t}}\right.$ ) and Mean Conditioned Standardised Return of Log Relatives (MCSR_LIR $\mathrm{t}_{\mathrm{t}}$. $\log$ of Index Relative i.e., $\mathrm{LIR}_{\mathrm{t}}$ is defined for every consecutive 1D index figure. Mean Return of Log Index Relative i.e., MR_LIR $\mathrm{t}_{\mathrm{t}}$ is calculated as the arithmetic mean of the recent past thirty $\operatorname{LIR}_{\mathrm{t}}$ data that is, for $t=-1,-2, \ldots-30$. Standardized Return of the same i.e., $S R \_L I R_{t}$ is defined as the $\operatorname{LIR}_{t}$ divided by the

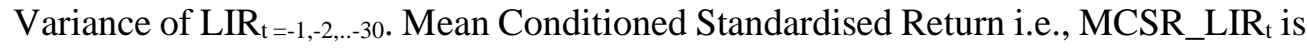
defined as Mean Return of Log Index Relative MR_LIR $\mathrm{t}_{\mathrm{t}=-1,-2, \ldots-30)}$ divided by the

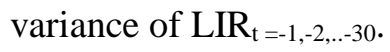

The risk parameters of these four return variables are defined with the variance definition of the respective return variables and the same is calculated for their recent past thirty return data, that is, for $t=-1,-2, \ldots-30$. These risk variables are VLIR $\mathrm{R}_{\mathrm{t}(\mathrm{t}=-}$

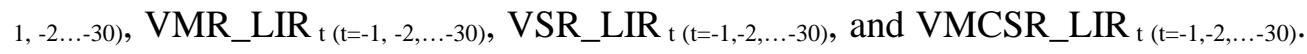
The asymmetry and kurtosis parameters are defined with the measure of skewness and kurtosis respectively for each of these four return variables. The skewness

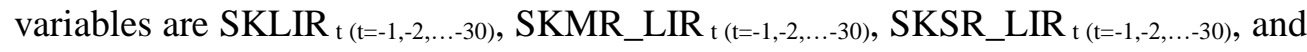

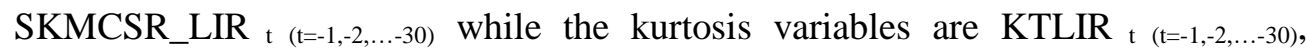

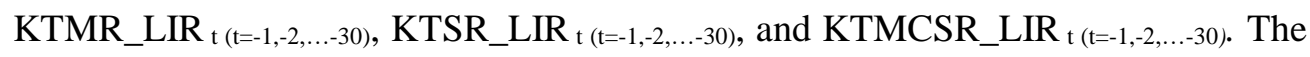
above data are compiled with the help of Microsoft Excel 2016, and then these are utilised in the Minitab-17 statistical software. In exploring the distributional properties, we examine the Anderson Darling (AD) normality tests for each of the variables of the stock market return, risk of returns, skewness of returns, and kurtosis of returns.

\section{Adaptive Learning Criteria for Decision Choices}

Based on the view of Nash equilibrium, the Adaptive learning models are inherently 'irrational' even though sensible. A trader here thinks of a partial selfadjusting behaviour but assumes inertia in others' actions. Such decision choice may be based on belief learning (BL), reinforcement learning (RL) or may be linked to experience-weight attraction (EWA) learning (Camerer \& Ho, 1999). Amongst these competitive models, the EWA learning model is an inclusive and superior one. It incorporates both the BL and RL criterion as its special cases. The EWA model allows individual difference in learning. For details about the EWA learning model, the readers are referred to Chen and $\mathrm{Du}$ (2017). The parameters in the EWA learning model are remotely used in marketing research (Ho, Lim, \& Camerer, 2006). The same can also be used in simulation of portfolio selection (Steinbacher, 2012) and economic guessing (Chen \& Du, 2017).

At the core of these models, intraday traders' choices need strategy. Strategies have numerical 'attractions' and these attractions determine their choice probabilities. 
Each player needs to specify his initial attractions, update the mechanism, and effects of attractions on choice probabilities. Camerer and Ho (1999) have showed that in a non-cooperative game, players adopt toward the equilibrium and the EWA model combines elements of the BL and RL models as special cases. The EWA model is an n-person normal form of game ${ }^{3}$, with four parameters which include the relative weight of foregone payoffs, two growth of attraction parameters viz., the decay of early attraction and that of strength of prior belief, and the strength of initial attraction. The model assumes each strategy has a numerical payoff and the same determines probability of choosing that strategy.

In the BL model, on the contrary, Camerer and Ho (1999) assume that players keep track of the history of the previous play by other players and establish a belief about others' possible future strategy based on past observation, and given the beliefs they formed, they then choose the best response strategy to maximise their expected payoffs. The BL model leads us towards herd behaviours. In the RL model, they assume that the strategies are reinforced by the previous payoffs and that the propensity to choose a strategy depends on its stock of reinforcement. Players who learn by reinforcement do not generally have beliefs about other players' strategies. In the BL model, players do not care about past successes (reinforcements) of chosen strategies. In the RL model, players care only about strategies resulting effective payoff in the past but not about the history of play that created those payoffs.

Camerer and Ho (1999) have showed that the EWA model incorporates features of both the BL and RL models. The way in which the strategies are reinforced links the two models. In the RL model, the unchosen strategies are never reinforced. While in accordance with EWA model, the first feature is that the un chosen strategies are reinforced based on a multiple $\delta$ of the payoffs the players would have earned in the RL model. When analysing the BL model, attractions are the expected payoffs, which are bounded by the range of the matrix payoffs. In the EWA model, attractions are the numbers that monotonically related to the probability of choosing a strategy. The EWA model assumes that the growth rates of attractions vary between the two bounds of the range. The second feature is that the growth rate decays at the rate of $\phi$ for past attraction and at the rate of $\rho$ for experience. Further, EWA model assumes initial attraction and experience weight. In BL model, initial attraction must be expected pay offs given prior beliefs. On the other hand, under the RL model, initial attractions are unrestricted. Furthermore, in the EWA model, initial attractions are unrestricted too.

3 The normal form representation of a game includes all perceptible and conceivable strategies, and their corresponding payoffs, for each player. 
In the following, we explore the distributional properties of the MMN with the two decay variables of $\phi$ and $\rho$ along with the weights of experience strength $N(p)$.

\section{Market Microstructure Noise and EWA Learning}

In the presence of MMN within the market return data of different definitions, our methodology proposes that the statistics of the market returns can be explained by parameters of the Experience Weight Attraction (EWA) learning method of Camerer and Ho (1999). In exploring the EWA method of learning by intraday traders, we use four decision parameters viz., the return location parameter, the variance -scale parameter, and the skewness and kurtosis, two characteristic exponent parameters. The concerned parameters in the EWA model are:

i. $\delta$, the relative weight parameter of foregone payoffs;

ii. $\phi$, the rate of decay of past attraction or early belief;

iii. $\quad \rho$, the rate of decay of strength of the experience measure; and

iv. $\quad \mathrm{N}(\mathrm{p}) \mathrm{t}$, experience weight being used to update the initial attraction level $A_{i}{ }^{j}(0)$.

When identifying the presence of MMN within the EWA learning model by traders in the BSE Sensex and NSE Nifty markets, we empirically explore the EWA learning parameters for these two stock market statistics. We abort exploration of the parameter $\delta$, the relative weight parameter of the foregone payoffs since it involves a detailed investment strategy. With the statistics of the stated decision parameters which include the return measure, risk measure, skewness measure, and kurtosis measure, we derive the data for decay of past attraction or early belief $(\phi)$, that of strength of experience measure $(\rho)$, and weight of experience strength $\mathrm{N}(\mathrm{p})_{\mathrm{t}}$ to update an initial attraction level $\mathrm{A}_{\mathrm{i}}^{\mathrm{j}}(0)$. The methodology is applicable for the four alternative definitions of the return measure, risk measure, skewness measure, and kurtosis measure. In defining variables and deriving the empirical data, we consider few basic assumptions for the single-index model. This can be updated for multi-stocks portfolio model.

\section{EWA Variable Definitions and Data Generation}

In defining the market returns, alternative definitions are applied viz., the Relative Index term (RIL), the Mean Return term (MR_RIL), the Standardised Return term (SR_RIL), and the Mean Controlled Standardised term (MCSR_RIL). We assume that a hypothetical intraday trader is considering his trading decisions in the NSE or BSE listed stock scripts. It is also assumed that the aggregate market sentiment depicted in terms of market returns and their higher order moments in the NSE Nifty 
or BSE Sensex are the only decision information. It is also assumed that different definitions of the market return can proxy for the long memory of the aggregate market sentiments of the trader. In the following, we now construct an empirical framework for single-index portfolio investment with the NSE Nifty and BSE Sensex alternatively.

Let us consider that on the dates of intraday trading (read with Appendix 1) in the market viz., NSE Nifty or BSE Sensex, each trader maintains his active observation window $\mathrm{A}_{1}^{\mathrm{j}}(0)$ and its strengths $\mathrm{N}(\mathrm{p})$ of the market movement for a continuous time lag length of $n_{1}$ munities. Once the value of the market return parameter viz., $\mathrm{RIL}_{\mathrm{t}}$ at $\mathrm{T}_{1}$ point in time exceeds that of $\mathrm{Tn}_{1}$ point in time, the trader recognizes an attraction strength $\mathrm{N}(\mathrm{p})$, where $\mathrm{p}$ is cumulative number of observations for the variable $\mathrm{RIL}_{\mathrm{t}}$. He keeps this stimulus attraction point in memory as his early attraction parameter and thereby, forms a belief for possible purchase or sale. On a continuous cumulative time basis, the trader updates his early attraction strength $\mathrm{N}(\mathrm{p})_{\mathrm{t}=0}$ over the time points of $\mathrm{Tn}_{2}$ being his experience measure time horizon. The magnitudes of $\mathrm{n}_{1}$ and $\mathrm{n}_{2}$ depend on his behavioural and psychological preferences and biases. At flexibility for his behavioural choice about $\mathrm{n}_{1}$ and $\mathrm{n}_{2}$, the trader's early attraction strength $\mathrm{N}(\mathrm{p})_{\mathrm{t}}$ $=0$ changes and so for his experience measure time horizon $\mathrm{Tn}_{2}$ as well.

Now, in the EWA learning model, the trader finds two dynamic weights of decay rates: $\phi$ for early attraction and $\rho$ for experience measure. At any trade time point $t, t$ $=0,1,2, \ldots \mathrm{n}$, the trader has a past attraction time horizon $\mathrm{T}_{\mathrm{t}}$ to $\mathrm{T}_{0}$ (i.e., a $\mathrm{T}_{\mathrm{t}}$ for past $1001 \mathrm{D}$ LIR data, or any return data) and an experience strength over time horizons $\mathrm{T}_{1}$ to $\mathrm{T}_{+\mathrm{t}}$ (i.e., a $\mathrm{T}_{+\mathrm{t}}$ for next 100 1D LIR data, or any return data). The rate of decay (i.e., reinforce) of his past attractions is $\phi$ and that of the experience measure is $\rho_{t}$. An experience weight strength is being placed to the initial past attraction level and experience strength level [N(1) and $\mathrm{N}(\mathrm{p})_{\mathrm{t}}$ respectively]. Based on the intraday $1 \mathrm{D} \mathrm{LIR} t$ data, we now generate data for these parameters. The summarized steps of the data generation technique are added in Appendix 2. For possible replication, the researchers are referred to Chen and $\mathrm{Du}$ (2017, pp. 4-6). We thereafter generate the same data for the other definitions of the rerun variable accordingly. Since the objective of the intraday trader is to earn greater returns, we need to recognize presence of greater noisy environment and higher arbitrage opportunity. Hence, we identify attraction points for the risk measure - variance, asymmetry measure skewness, and pickiness measure - kurtosis. An attraction point is also defined as being a greater risky point, greater asymmetry point, and a greater kurtosis point. In doing so, the study extends its scope beyond exploring the intraday returns of the NSE Nifty and BSE Sensex. The data for the respective three new parameters is now 
processed in the Minitab-17 statistical software along with those for the return data in deriving their distributional summary statistics. We report the same under the following headings and put forward a brief discussion.

\section{Empirical Findings and Discussions}

We firstly examine distributional properties of intraday NSE Nifty and BSE Sensex stock market returns and their higher order moments (viz., variance, skewness, and kurtosis) whether they follow the normal distribution or not. Once we reveal the same, we then examine the EWA learning behaviour of a hypothetical intraday trader considering the stock market returns and their higher order moments as the basic information for decision choices. Here, we examine the magnitude of the experience weight and two decay rates in the EWA learning model of Camerer and Ho (1999) with the market returns and their higher order moments whether they follow the normal distribution or not. Besides, we examine the generalisability of the findings in a reader friendly manner.

\section{Market Statistics and Market Microstructure Noise}

We explore the distributional properties of the said 16 variables: the return variable in Table 1 (for the BSE Sensex data) and Table 1A (the NSE Nifty data), the risk variables in Table 2 (the BSE data) and Table 2A (the NSE data), the skewness variables in Table 3 (the BSE data) and Table 3A (the NSE data), and the kurtosis variable in Table 4 (the BSE data), Table 4A (the NSE data). Here, the null hypothesis is that the stock market returns and their higher order moments are normally distributed and the same is accepted in the Anderson Darling (AD) test. At normality, the values of skewness and kurtosis measures of the parameters under interest are zero. The relevant alternative hypothesis is that the returns and their higher order moments are non-normal and the AD test rejects the null hypothesis. The results are now briefly discussed.

Table 1 shows that the AD Test rejects the null hypothesis for the return variables. The intraday logarithm value of the BSE Sensex open index LnBSE_Open and the alternative return variables $\mathrm{LIR}_{\mathrm{t}}, \mathrm{MR}_{-} \mathrm{LIR}_{\mathrm{t}}, \mathrm{SR}_{-} \mathrm{LIR}_{\mathrm{t}}$, and $\mathrm{MCSR} \_L I R_{t}$ are nonnormal. Their respective combinations of skewness and kurtosis are $(-0.98264$, $2.2314),(-0.00197,1.13321),(0.00733,1.09251),(-0.15979,4.67174)$ and $(0.168$, 133.835). The variables LnBSE_Open, $L_{2} R_{t}$ and SR_LIR are negatively skewed while those of MR_LIR and MCSR_LIR are positively skewed. These positive (negative) magnitudes of the kurtosis measure reveal that returns at different definitions have 
heavier (lighter) tails than normal distribution and extreme data points have greater or lesser effects than their central data points.

Table 1: Basic Summary Statistics of the Log Indexes and Return Variables for BSE Sensex

\begin{tabular}{lrrrrr}
\hline Particulars & $\begin{array}{r}\text { LnBSE_ } \\
\text { Open }\end{array}$ & LIR & MR_LIR & SR_LIR & MCSR_LIR \\
\hline $\begin{array}{l}\text { A-Squared (AD } \\
\text { Normality Test) }\end{array}$ & 549.96 & 161.99 & 118.14 & 231.05 & 779.44 \\
$p$-Value (AD & & & & & \\
Normality Test) & $<0.005$ & $<0.005$ & $<0.005$ & $<0.005$ & $<0.005$ \\
Mean & 10.241 & $-2 \mathrm{E}-06$ & 0 & -0.416 & 0.0076 \\
Standard Deviation & 0.019 & 0.026564 & 0.00089 & 42.266 & 1.8421 \\
Variance & 0 & 0.000706 & 0.000001 & 1786.396 & 3.3932 \\
Skewness & -0.98264 & -0.00197 & 0.00733 & -0.15979 & 0.168 \\
Kurtosis & 2.2314 & 1.13321 & 1.09251 & 4.67174 & 133.835 \\
$\mathrm{~N}$ & 26232 & 26231 & 26202 & 26202 & 26202 \\
\hline
\end{tabular}

The measure of Kurtosis looks at the combined size of the two tails. It interprets tail extremity unambiguously and determines the shapes of distributions largely (Westfall, 2014). Kurtosis decreases (increases) as tails become lighter (heavier). The negatively skewed heterogeneous LIR data become positively skewed once it is transformed at its mean level, MR_LIR. This reveals that scaling with an arithmetic mean (with reference to thirty-timestamp data) does not homogenise LIR. This apprehension becomes even more evident once LIR data is standardized at SR_LIR level. Such standardisation makes SR_LIR data more heterogeneous with higher kurtosis value and negatively skewed as well. The heterogeneity effect in LIR data is robustly observed in MR_LIR data once the same is standardized and transformed into MCSR_LIR data. Data transformation reveals greater heterogeneity and shows higher values for both skewness and kurtosis measures with MCSR_LIR data.

Why do these standardisations reveal greater heterogeneity? What does heterogeneity within data mean for the market microstructure? For the time being, we seemingly assume that the data reveal what the data are. Thus, returns data appear asymmetric and these involve systematic noise. Their stability varies in the market. Further standardisation shows greater uncertainty in the market returns. The more LIR data is smoothened, controlled and standardized the greater it reveals the uncertainty for intraday return within the market microstructure. Since the present 
exploration utilises a univariate data of the stocks' timestamp market prices, we call this uncertainty as MMN. The noise is generated within the dynamic pricing system of the market. Hence, even if there is an absence of any test statistics measuring MMN, the presence of noise is evident and pervasive. Table 1 briefly signifies that out of the four alternative definitions for BSE Sensex returns, in two cases data distribution is highly exposed to few extreme lesser (higher) values and lowly exposed to frequent greater (lower) values, that is, negatively (positively) skewed. Such MMN reveals deviation from normal and symmetric information distribution with the intraday high frequency trading data and these persist even after standardisation of $\mathrm{LIR}_{\mathrm{t}}$ to $\mathrm{SR}_{-} \mathrm{LIR}_{\mathrm{t}}$ and $M R \_L I R_{t}$ to MCSR_LIR $\mathrm{t}$. These confirm persistent presence of MMN.

Table 1A: Basic Summary Statistics of the Log Indexes and Return Variables for NSE Nifty

\begin{tabular}{lrrrrr}
\hline Particulars & $\begin{array}{r}\text { LnNSE_ } \\
\text { Open }\end{array}$ & LIR & MR_LIR & SR_LIR & MCSR_LIR \\
\hline $\begin{array}{l}\text { A-Squared (AD } \\
\text { Normality Test) }\end{array}$ & 1161.92 & 3971.98 & 3345.42 & 342.03 & 105.71 \\
$\begin{array}{l}p \text {-Value (AD } \\
\text { Normality Test) }\end{array}$ & $<0.005$ & $<0.005$ & $<0.005$ & $<0.005$ & $<0.005$ \\
Mean & 9.0565 & 0.000001 & 0.000001 & -18.3 & 33.14 \\
Standard Deviation & 0.0262 & 0.000628 & 0.000114 & 5071.9 & 845.79 \\
Variance & 0.0007 & 0 & 0 & 25724093 & 715356.7 \\
Skewness & -0.89276 & 41.01 & 6.96 & 0.00131 & 0.07506 \\
Kurtosis & 0.114752 & 4834.4 & 156.599 & 3.21175 & 1.96627 \\
$\mathrm{~N}$ & 31166 & 31165 & 31136 & 31136 & 31136 \\
\hline
\end{tabular}

With regard to the NSE Nifty data, results in Table 1A show that the AD Test rejects the proposition of normality distribution of the return variables. Here, the results for the LnNSE_Open and the related data for four return variables show that the data distribution is negatively skewed for the log indexed NSE open index but positively skewed for all definitions of market return variables. The kurtosis for LnNSE_Open shows that the log indexed values are leptokurtic. The parameters in the summary report show clear differences in terms of values of the skewness and kurtosis of these parameters. These results suggest for the presence of heterogeneity across markets. The observed heterogeneity reveals that traders in these markets move at too much noisy directions. With the data of SR_LIR and MCSR_LIR, the above stated heterogeneity persists even after standardisation of the LIR data. This 
validates our findings for the NSE Nifty returns. The standardized data also reveals that the degree of heterogeneity varies with reference to the relevant markets.

Table 2: Basic Summary Statistics of Variance of the Four Return Variables for BSE Sensex

\begin{tabular}{lrrrr}
\hline Particulars & VLIR & VMR_LIR & VSR_LIR & VMCSR_LIR \\
\hline A-Squared (AD & & & & \\
Normality Test) & 178.92 & 122.99 & 1976.54 & 8112.68 \\
$p$-Value (AD & & & & \\
Normality Test) & $<0.005$ & $<0.005$ & $<0.005$ & $<0.005$ \\
Mean & 0.000729 & 0.000001 & 1822.4 & 2.866 \\
StDev & 0.000307 & 0 & 1648 & 14.054 \\
Variance & 0 & 0 & 2715998 & 197.503 \\
Skewness & 0.719797 & 0.526911 & 11.915 & 22.729 \\
Kurtosis & 0.546721 & 0.05135 & 227.135 & 556.282 \\
$\mathrm{~N}$ & 26231 & 26202 & 26202 & 26202 \\
\hline
\end{tabular}

Statistics in Table 2 about the BSE Sensex data illustrate that variances at different variable definitions are non-normal in distribution and positively skewed, and their kurtosis values increase exponentially when there is an increase in the magnitudes of skewness measure. The variance of MR_LIR $_{t}$ variable (i.e. VMR_LIRt) data have least magnitude of 0.526911 and 0.05135 for the skewness and kurtosis measures respectively while that of MCSR_LIR $\mathrm{t}_{t}$ variable (i.e. VMCSR_LIR $_{t}$ ) data have 22.729 and 556.282 respectively. These observations suggest that the intraday trade data at the BSE Sensex Stock Market also involve scaling effects in the manipulation of variable definition. In other words, once the return data $\mathrm{LIR}_{\mathrm{t}}$ and MR_LIR $\mathrm{t}$ are smoothened and standardised, the variables $V_{\text {VSR_LIR }}$ and VMCSR_LIR $\mathrm{t}_{\mathrm{t}}$ data become highly positively skewed and highly leptokurtic in their distributions. All these information confirm that the varience data is contaminated by hetrosecdasticity effects and such hetrosecdasticity effect is originated in different strata of data. Hence, there is robust presence of uncertainty or MMN in the intraday returns at the BSE Sensex market data.

Results in Table 2A about the NSE data for the variance definitions also confirm rejection of the normal distribution for the variance variables. The statistics for these variables show the stylised fact that variances of returns data are positively skewed and leptokurtic, and the both measures have positive relationship that is when kurtosis increases exponentially at the increase in the level of skewness. These findings demonstrate the robust presence of noise in the market variance data. We 
now emphasise that smoothening and standardising the market return data makes the market varianve data less skewed and less leptokurtic in their distributions. The scaling effect is somewhat opposite to what we have observed in the earlier case with the BSE data. The scaling effects in the manipulation of variable definition do not necessarily induce heteroskedasticity and here, they reduce heteroskedasticity or noise in the NSE market. These hint for some alternative implications such that the noise has different dimensions viz., local and global effects. The smoothening or standardisation process of the trader at his EWA learning decision choices should not be a straightjacket in revealing such local, global or variable specific effects.

Table 2A: Basic Summary Statistics of Variance of the Four Return Variables for NSE Nifty

\begin{tabular}{lrrrr}
\hline Particulars & VLIR & VMR_LIR & VSR_LIR & VMCSR_LIR \\
\hline A-Squared (AD & & & & \\
Normality Test) & 11157.26 & 10823.87 & 1267.49 & 2723.08 \\
$p$-Value (AD & & & & \\
Normality Test) & 0.005 & $<0.005$ & $<0.005$ & $<0.005$ \\
Mean & 0 & 0 & 25691910 & 318734 \\
StDev & 0.000005 & 0 & 23010062 & 412907 \\
Variance & 0 & 0 & $5.29 \mathrm{E}+14$ & $1.70 \mathrm{E}+11$ \\
Skewness & 22.481 & 17.864 & 2.18312 & 4.2094 \\
Kurtosis & 547.39 & 360.003 & 7.5545 & 31.4768 \\
N & 31136 & 31107 & 31107 & 31107 \\
\hline
\end{tabular}

Given the non-normality and hetrogeniety of the market return and its variance at the different definitions, we now explore if the skweness and kurtosis measures of the skewness data set also suggest for unstable non-normal distributions. For this purpose, we explore the characteristic parameters of the skewness data sets.

The statistics in Table 3 show that distribution of the skewness data is nonnormal. The mean value of the skewness parameter is non-zero with an approximate variance value ranging within $1 / 5$ and $3 / 5$, in particular, the magnitudes are 0.21786 for SKLIR, 0.38188 for SKMR_LIR, 0.19638 for SKSR_LIR SKMCMR_LIR . The negative (positive) values of the mean skewness measure show that investors are exposed to few extreme losses (gains) but frequent small gains (losses) (read with Ardliansyah, 2012). The skewness statistics for the "skewness variable" are non-zero and these show their respective values of $0.097065,0.035421$, 0.02368 and 0.09385 depending on the different definitions our return measurement 
and therefore, their distributions are asymetric in nature. These confirm regularity in the assymetry feature in the market return data. The magnitudes of the measure of kurtosis for the skewness variables SKLIR $_{t}, S K M R \_L I R, S K M C M R \_L I R+$ and SKSR_LIR ${ }_{t}$ are remarkably leptokurtic in nature while SKSR_LIR ${ }_{t}$ definition has the magnitude of 2.26291. These results confirm that the asymmetry within the market return is unevenly distributed. The assymetry is hetrosecdastically originated in the different strata of return data. These observations substantiate for presence of nonnormal unstable distribution for the retun data at their various definitions.

Table 3: Basic Summary Statistics of Skewness of the Four Return Variables for BSE Sensex

\begin{tabular}{lrrrr}
\hline Particulars & SKLIR & SKMR_LIR & SKSR_LIR & SKMCSR_LIR \\
\hline A-Squared (AD & 20.75 & 5.36 & 38.77 & 45.75 \\
Normality Test) & & & & \\
$p$-Value (AD & $<0.005$ & $<0.005$ & $<0.005$ & $<0.005$ \\
Normality Test) & -0.00387 & 0.00987 & -0.14101 & 0.00995 \\
Mean & 0.46675 & 0.61796 & 0.44315 & 0.75074 \\
StDev & 0.21786 & 0.38188 & 0.19638 & 0.56361 \\
Variance & 0.097065 & 0.035421 & 0.02368 & 0.09385 \\
Skewness & 0.596664 & 0.278255 & 2.26291 & 1.00574 \\
Kurtosis & 26231 & 26202 & 26202 & 26202 \\
N & & & & \\
\hline
\end{tabular}

Results in Table 3A also illustrate non-normallty of distribution of skewness variables for the NSE Nifty data. The mean statitstics of the skewness parameter again are non-zero. The relevant variance statistics expose more presence with the magnitudes of $1.25744,0.46904,0.63507$ and 0.66367 for the stated scaling effect in the NSE intraday trade data than that in the BSE data. Evidently, there is immense microstructure noise in the NSE market and this noise leads to hetrogeniety effects within the skewness data. Further, the heterogeneity effect is apprehended with the leptokurtic nature of the distributions of the variables for skewness.

Table 3A: Basic Summary Statistics of Skewness of the Four Return Variables for NSE Nifty

\begin{tabular}{lcccc}
\hline Particulars & SKLIR & SKMR_LIR & SKSR_LIR & SKMCSR_LIR \\
\hline $\begin{array}{l}\text { A-Squared (AD } \\
\text { Normality Test) }\end{array}$ & 1106.28 & 107.79 & 183.62 & 152.44 \\
$\begin{array}{l}p \text {-Value (AD } \\
\text { Normality Test) }\end{array}$ & $<0.005$ & $<0.005$ & $<0.005$ & $<0.005$ \\
\hline
\end{tabular}




\begin{tabular}{lrrrr}
\hline Particulars & SKLIR & SKMR_LIR & SKSR_LIR & SKMCSR_LIR \\
\hline Mean & 0.04673 & 0.00063 & -0.00381 & 0.00578 \\
StDev & 1.12136 & 0.68486 & 0.79691 & 0.81466 \\
Variance & 1.25744 & 0.46904 & 0.63507 & 0.66367 \\
Skewness & 0.36891 & 0.01208 & 0.14847 & -0.07335 \\
Kurtosis & 6.67324 & 4.79786 & 3.93458 & 4.14881 \\
N & 31136 & 31107 & 31107 & 31107 \\
\hline
\end{tabular}

The stylised observations, for the different returns, variances and skewness measures of BSE Sensex and NSE Nifty markets would be, that these are non-normal in distribution and they infer about unstable distribution about the intraday stock market returns. On a robustness check, we explore the skewness and kurtosis measures of the kurtosis data set of the market returns.

Table 4: Basic Summary Statistics of the Kurtosis of the Return Variables for BSE Sensex

\begin{tabular}{lrrrr}
\hline Particulars & KTLIR & KTMR_LIR & KTSR_LIR & KTMCSR_LIR \\
\hline A-Squared (AD & & & & \\
Normality Test) & 500.62 & 483.51 & 38.77 & 846.04 \\
$p$-Value (AD & & & & \\
Normality Test) & $<0.005$ & $<0.005$ & $<0.005$ & $<0.005$ \\
Mean & 0.951 & 1.0369 & -0.14101 & 1.5425 \\
StDev & 1.3218 & 1.3043 & 0.44315 & 1.8481 \\
Variance & 1.7472 & 1.7012 & 0.19638 & 3.4153 \\
Skewness & 1.41017 & 1.45518 & 0.02368 & 1.88275 \\
Kurtosis & 3.24853 & 3.76546 & 2.26291 & 5.71826 \\
N & 26231 & 26202 & 26202 & 26202 \\
Minimum & -1.413 & -1.3679 & -4.2785 & -1.4143 \\
1st Quartile & 0.0082 & 0.1345 & -0.4144 & 0.2876 \\
Median & 0.6838 & 0.7831 & -0.14169 & 1.0662 \\
3rd Quartile & 1.5853 & 1.6486 & 0.13006 & 2.3026 \\
Maximum & 12.0939 & 12.0152 & 3.78742 & 17.1498 \\
\hline
\end{tabular}

The reselts in Table 4 for the BSE data shows that the mean (viz., 0.951, 1.0369, -0.14101 , and 1.5425) and skewness (1.41017, 1.45518, 0.02368, and 1.88275) measures of the kurtosis parameter (viz., KTLIR, KTMR_LIR, KTSR_LIR, and KTMCSR_LIR) suggest for positively skewed distribution for the stated different kurtosis measures corresponding to their different return definitions. The reported 
mean statistics for the kurtosis measures are either positive or negative. The magnitudes of the kurtosis in Table 4 show non-normality for all the four definition

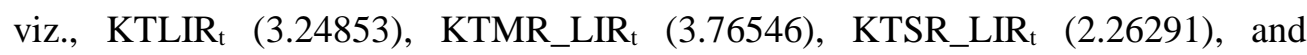
KTMCSR_LIR $\mathrm{t}_{\mathrm{t}}$ (5.71826). It is evident that the first quartile of kurtosis statistics for

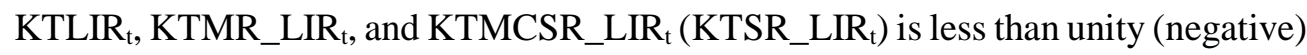
while the third quartile is more than unity (positive). It is worth mentioning that the median value of the kurtosis statistics is non-zero. These results confirm the asymmetry and heterogeneity within different strata of stock market returns. Above information suggest that at different definitions, the return data are unstable and nonnormal in distributions.

Table 4A: Basic Summary Statistics of the Kurtosis of the Return Variables for NSE Nifty

\begin{tabular}{lrrrr}
\hline Particulars & KTLIR & KTMR_LIR & KTSR_LIR & KTMCSR_LIR \\
\hline A-Squared (AD & & & & \\
Normality Test) & 4614.78 & 2488.6 & 2376.24 & 3014.8 \\
$p$-Value (AD & $<0.005$ & $<0.005$ & $<0.005$ & $<0.005$ \\
Normality Test) & 1.8446 & -0.2783 & 1.1097 & 0.0729 \\
Mean & 4.4568 & 1.6099 & 2.3669 & 2.1035 \\
StDev & 19.8631 & 2.5916 & 5.6023 & 4.4247 \\
Variance & 3.7298 & 7.3802 & 4.1083 & 6.0715 \\
Skewness & 15.5459 & 95.7282 & 27.5804 & 58.075 \\
Kurtosis & 31136 & 31107 & 31107 & 31107 \\
N & -1.4538 & -2.1476 & -1.4666 & -2.0024 \\
Minimum & -0.184 & -1.0467 & -0.1914 & -0.9254 \\
1 st Quartile & 0.4873 & -0.6001 & 0.4572 & -0.4194 \\
Median & 1.6981 & 0.0308 & 1.5894 & 0.3672 \\
3rd Quartile & 29.9815 & 29.8863 & 29.9692 & 29.9997 \\
Maximum & & & & \\
\hline
\end{tabular}

The results for the Kurtosis variable of the market returns of different definitions in Table 4A also reflect similar findings for the NSE Nifty market's intraday index data as well. The difference is that the higher order statistics of the kurtosis parameter are low in magnitude for the BSE Sensex data but high for the NSE Nifty data. The pickiness of the NSE data for the kurtosis of return confirms greater heterogeneity in the NSE market than that in the BSE market. These show non-stability in the dynamic pricing process of the concerned scripts in the BSE Sensex and NSE Nifty indices as 
well. The measures of skewness and kurtosis variable definitions show that heterogeneity lies within the both BSE and NSE market returns data. The stated heterogeneity confirms the underlying uncertainty in the market or the MMN. But what causes the stated heterogeneity or noise within the market data? Does the human behaviour help in exploring such Market Microstructure Noise?

\section{EWA Statistics and Market Microstructure Noise}

We explore the distributional properties of the three parameters in the EWA model against the variables of market return, variance, skewness measure and kurtosis for the alternative definitions of returns. The observations for the NSE and BSE data for the three variables $\mathrm{N}(\mathrm{p})_{\mathrm{t}}, \phi_{t}$, and $\rho_{t}$ are processed and results of the Graphical Summary Statistics in Minitab17 are depicted in the following tables. The results for the four definitions of the return variable are depicted in Tables 5A, 5B, 5C, and 5D, those for the risk definition in Tables $6 \mathrm{~A}, 6 \mathrm{~B}, 6 \mathrm{C}$, and $6 \mathrm{D}$, the skewness definition in Tables 7A, 7B, 7C, and 7D, and the kurtosis definition in Tables 8A, 8B, 8C, and 8D respectively. The results are also discussed.

Table 5A: Statistics of EWA Parameters and Retun Variable LIR for NSE Nifty and BSE Sensex

\begin{tabular}{|c|c|c|c|c|c|c|}
\hline \multirow{2}{*}{ Particulars } & \multicolumn{3}{|c|}{ EWA Statistics for NSE Nifty } & \multicolumn{3}{|c|}{ EWA Statistics for BSE Sensex } \\
\hline & $\mathbf{N}(\mathbf{p})_{t}$ & $\phi_{t}$ & $\rho_{t}$ & $\mathbf{N}(\mathbf{p})_{t}$ & $\phi_{t}$ & $\rho_{t}$ \\
\hline $\begin{array}{l}\text { A-Squared (AD } \\
\text { Normality Test) }\end{array}$ & 5522.82 & 5533.31 & 2531.02 & 3332.78 & 4395.12 & 2534.69 \\
\hline $\begin{array}{l}p \text {-Value (AD } \\
\text { Normality Test) }\end{array}$ & $<0.005$ & $<0.005$ & $<0.005$ & $<0.005$ & $<0.005$ & $<0.005$ \\
\hline Mean & 0.49938 & 0 & $-1 \mathrm{E}-06$ & 0.50083 & 0.000001 & 0.000002 \\
\hline StDev & 0.00605 & 0.000282 & 0.007126 & 0.00459 & 0.000308 & 0.006497 \\
\hline Variance & 0.00004 & 0 & 0.000051 & 0.00002 & 0 & 0.000042 \\
\hline Skewness & 48.73 & 0.1726 & 0.00019 & -48.38 & 0.7903 & -0.00019 \\
\hline Kurtosis & 3519.66 & 99.8865 & -1.03069 & 5542.24 & 84.453 & -0.63058 \\
\hline $\mathrm{N}$ & 31066 & 30965 & 30965 & 26161 & 26060 & 26060 \\
\hline Minimum & 0.42424 & -0.00485 & -0.01 & 0 & -0.00467 & -0.01 \\
\hline 1st Quartile & 0.49797 & $-3.2 \mathrm{E}-05$ & -0.01 & 0.49985 & $-3.8 \mathrm{E}-05$ & 0 \\
\hline Median & 0.49896 & $-1.6 \mathrm{E}-05$ & 0 & 0.5007 & 0.000019 & 0 \\
\hline 3rd Quartile & 0.50032 & 0.000032 & 0.01 & 0.50168 & 0.000038 & 0 \\
\hline Maximum & 1 & 0.00495 & 0.01 & 0.66667 & 0.005145 & 0.01 \\
\hline
\end{tabular}


In Table 5A, we illustrate our results with the parameters in the EWA learning model for the LIR returns data of the market indices viz., the BSE Sensex and NSE Nifty. These parameters are: the decay rate of early attraction $(\phi)$ and the decay rate of strength of experience measure $(\rho)$, and the experience weight, $\mathrm{N}(\mathrm{p})_{\mathrm{t}}$. These parameters are used to update the initial attraction level. In brief, the Table shows that the mean of strength of experience weight $\mathrm{N}(\mathrm{p})_{\mathrm{t}}$ is near to half $(0.49938$ for the NSE and 0.50083 for the BSE), skewed and leptokurtic in nature. The mean of decay of early attraction shows that it is about to zero, positively skewed and leptokurtic. The decay rate for experience measure is minimally skewed and platykurtic and therefore, stable in nature. The behavioural distributions of the stated three adaptive learning parameters are non-normal for both stock markets' intraday returns, LIR data. Now, diving down the data of $\mathrm{N}(\mathrm{p})_{\mathrm{t}}$ reveals that intraday traders have mid-way expectation probability at experience weight in the markets for strengthening their experiences. Intraday traders are not indifferent in gaining greater experience and thereto, at utilising the same for further trading or fixing their target trade objectives. They can enhance experience strength $\mathrm{N}(\mathrm{p})_{\mathrm{t}}$ favourably and tuning their trading gains in either of the markets and the same ranges with the minimum to maximum ranges of 0.42424 -1 and $0-0.66667$ in the NSE Nifty and BSE Sensex markets respectively.

The relevant skewness and kurtosis measures show an unstable and noisy nature of the strength of experience weight. These all make a sense of uniformity with the said ranges of expectation weights. The decay rate of early attraction also appears motivating towards explaining the adaptive behavioural attributes. The average rate of the same is about to zero while it lies within the ranges of -0.00485 to 0.00495 and -0.00467 to 0.005145 for traders in the NSE and BSE respectively. These observations along with the leptokurtic distributions of the parameter signify the persistency of noise in the decay rate of early attraction. The mean, median and mode values for the earlier attractions parameter if read with the decay rate of earlier attraction parameter suggest that earlier attractions even if do not die off in the traders' memories, these have dynamic and noisy effects. The same are also reflected with the positively skewed leptokurtic distributions of the decay rate of earlier attraction.

Furthermore, the decay rate for experience measure, $\rho$ is minimally skewed and platykurtic and therefore, stable in nature. This relevant decay rate has zero mean with a range of -0.01 and 0.01 in both the markets. These show minimal exposure of the decay of experience measure and they hint at uniformity in decay of experience exposure. The dynamic nature of MMN persists. In effect, the said uniformity shows that the traders' dynamic experiences in both markets do not die off in their experience exposures and these are reflected through the negatively skewed 
distributions. The traders' adaptive behaviours have opportunistic prospects about the decay of experience strength. Hence, the observations about the statistics of the EWA parameters in Table 5A show that intraday traders have dynamic, adaptive and forward-looking preoccupations in their experience strength but along with robust noise about the decay in their earlier attractions and experience strengths.

Table 5B: Statistics of EWA Parameters and Retun Variable MR_LIR for NSE Nifty and BSE Sensex

\begin{tabular}{lrrrrrr}
\hline \multirow{2}{*}{ Particulars } & \multicolumn{2}{c}{ EWA Statistics for NSE Nifty } & \multicolumn{4}{c}{ EWA Statistics for BSE Sensex } \\
\cline { 2 - 7 } & $\mathbf{N}(\mathbf{p})_{\mathbf{t}}$ & $\boldsymbol{\phi}_{\boldsymbol{t}}$ & $\boldsymbol{\rho}_{\boldsymbol{t}}$ & $\mathbf{N}(\mathbf{p})_{\mathbf{t}}$ & $\boldsymbol{\phi}_{\boldsymbol{t}}$ & $\boldsymbol{\rho}_{\boldsymbol{t}}$ \\
\hline A-Squared (AD & & & & & & \\
Normality Test) & 7439.88 & 5454.08 & 2491.95 & 5044.19 & 4397.69 & 2146.12 \\
$p$-Value (AD & & & & & & \\
Normality Test) & $<0.005$ & $<0.005$ & $<0.005$ & $<0.005$ & $<0.005$ & $<0.005$ \\
Mean & 0.50003 & $-1 \mathrm{E}-06$ & $-1.1 \mathrm{E}-05$ & 0.49568 & 0.000002 & 0 \\
StDev & 0.02433 & 0.000276 & 0.00808 & 0.00804 & 0.000308 & 0.007089 \\
Variance & 0.00059 & 0 & 0.000065 & 0.00006 & 0 & 0.00005 \\
Skewness & -13.551 & -1.909 & 0.00205 & -26.91 & 1.4153 & 0 \\
Kurtosis & 284.413 & 102.773 & -1.46841 & 1311.75 & 85.4572 & -1.01004 \\
N & 31066 & 30965 & 30965 & 26161 & 26060 & 26060 \\
Minimum & 0 & -0.00534 & -0.01 & 0 & -0.00448 & -0.01 \\
1st Quartile & 0.4975 & $-3.2 \mathrm{E}-05$ & -0.01 & 0.49421 & $-3.8 \mathrm{E}-05$ & -0.01 \\
Median & 0.49869 & 0.000016 & 0 & 0.49624 & 0.000019 & 0 \\
3rd Quartile & 0.50144 & 0.000032 & 0.01 & 0.49706 & 0.000038 & 0.01 \\
Maximum & 0.66514 & 0.004347 & 0.01 & 0.56637 & 0.005339 & 0.01 \\
\hline
\end{tabular}

In Table 5B, we perform a cross check of our observations in Table 5A. The results are releated to the alternative definition of the return data viz., the mean return of the log-index relatives (MR_LIR). The EWA statistics with MR_LIR for the two decay rates $\phi$ and $\rho$, and the experience weight $\mathrm{N}(\mathrm{p})_{\mathrm{t}}$ also confirm that intraday traders' opportunistic preoccupations about the said adaptive dynamic behaviours for experience measure, and the noisy environment about the decay rates for earlier belief and strength of experience. The mean of experience strength weight $\mathrm{N}(\mathrm{p})_{\mathrm{t}}$ is near to half, skewed and leptokurtic in nature. The decay of early attraction is also about to zero and positively skewed and leptokurtic. The decay rate for experience measure is also minimally skewed and platykurtic and stable. The distributions of the stated adaptive learning parameters are non-normal. To save space, we avoid any repetitive discussion in depth for the results in Table 5B. 
On the robustness check of the EWA statistics of the return data LIR and MR_LIR, we use the SR_LIR data alternatively. In Table 5C, the results for the relevant decay rates $\phi$ and $\rho$, and experience weight $N(\mathrm{p})_{\mathrm{t}}$ validate the tenability of the stated evidence that intraday traders have preoccupations about the adaptive dynamic behaviours for experience measure while noise about the decay of strength of experience and earlier belief can explain the existing market microstructure noise. The distributions of these three EWA parameters are non-normal in the NSE and BSE stock markets.

Table 5C: Statistics of EWA Parameters and Retun Variable SR_LIR for NSE Nifty and BSE Sensex

\begin{tabular}{lrrrrrr}
\hline \multirow{2}{*}{ Particulars } & \multicolumn{2}{c}{ EWA Statistics for NSE Nifty } & \multicolumn{4}{c}{ EWA Statistics for BSE Sensex } \\
\cline { 2 - 7 } & $\mathbf{N}(\mathbf{p}) \mathbf{t}$ & \multicolumn{1}{c}{$\boldsymbol{\phi}_{\boldsymbol{t}}$} & $\boldsymbol{\rho} \boldsymbol{t}$ & $\mathbf{N}(\mathbf{p}) \mathbf{t}$ & $\boldsymbol{\phi}_{\boldsymbol{t}}$ & $\boldsymbol{\rho}_{\boldsymbol{t}}$ \\
\hline A-Squared (AD & & & & & & \\
Normality Test) & 7192.34 & 5536.45 & 2540.9 & 6204.93 & 4404.88 & 2507.83 \\
$p$-Value (AD & & & & & & \\
Normality Test) & $<0.005$ & $<0.005$ & $<0.005$ & $<0.005$ & $<0.005$ & $<0.005$ \\
Mean & 0.49967 & $-1 \mathrm{E}-06$ & $-1 \mathrm{E}-06$ & 0.50234 & 0.000002 & 0.000003 \\
StDev & 0.008 & 0.000282 & 0.007107 & 0.0096 & 0.000309 & 0.006529 \\
Variance & 0.00006 & 0 & 0.000051 & 0.00009 & 0 & 0.000043 \\
Skewness & -35.84 & -0.862 & 0.00019 & 30.29 & 1.7317 & -0.00027 \\
Kurtosis & 1824.54 & 100.792 & -1.01986 & 1295.33 & 86.9348 & -0.65363 \\
N & 31066 & 30965 & 30965 & 26161 & 26060 & 26060 \\
Minimum & 0 & -0.00513 & -0.01 & 0.49544 & -0.00439 & -0.01 \\
1st Quartile & 0.49948 & $-3.2 \mathrm{E}-05$ & -0.01 & 0.50044 & $-3.8 \mathrm{E}-05$ & 0 \\
Median & 0.50015 & $-1.6 \mathrm{E}-05$ & 0 & 0.50117 & $-1.9 \mathrm{E}-05$ & 0 \\
3rd Quartile & 0.50084 & 0.000032 & 0.01 & 0.50283 & 0.000038 & 0 \\
Maximum & 0.51028 & 0.004659 & 0.01 & 1 & 0.005436 & 0.01 \\
\hline
\end{tabular}

A further robustness check with the alternative return data MCSR_LIR is also performed. The reported statistics in Table 5D for the two decay rates and the experience weight as well validate that even if MCSR_LIR definition for return data is being used, intraday traders show engagement in the adaptive dynamic behaviours for experience measure and the noise about the decay rate of strength of experience measure and earlier belief exist. Here as well, the distributions of adaptive learning parameters are non-normal in the NSE Nifty and BSE Sensex markets. 
Table 5D: Statistics of EWA Parameters and Retun Variable MCSR_LIR for NSE Nifty and BSE Sensex

\begin{tabular}{lrrrrrr}
\hline \multirow{2}{*}{ Particulars } & \multicolumn{7}{c}{ EWA Statistics for NSE Nifty } & \multicolumn{3}{c}{ EWA Statistics for BSE Sensex } \\
\cline { 2 - 7 } & $\mathbf{N}(\mathbf{p})_{\mathbf{t}}$ & \multicolumn{1}{c}{$\boldsymbol{\phi}_{\boldsymbol{t}}$} & $\boldsymbol{\rho}_{\boldsymbol{t}}$ & $\mathbf{N}(\mathbf{p})_{\mathbf{t}}$ & $\boldsymbol{\phi}_{\boldsymbol{t}}$ & $\boldsymbol{\rho}_{\boldsymbol{t}}$ \\
\hline A-Squared (AD & & & & & & \\
Normality Test) & 5716.71 & 5418.21 & 2489.82 & 6448.83 & 4399.24 & 2137.69 \\
& & & & & & \\
Normality Test) & $<0.005$ & $<0.005$ & $<0.005$ & $<0.005$ & $<0.005$ & $<0.005$ \\
Mean & 0.50746 & 0 & $-8 \mathrm{E}-06$ & 0.49593 & $-3 \mathrm{E}-06$ & $-4 \mathrm{E}-06$ \\
StDev & 0.02387 & 0.000274 & 0.008076 & 0.01298 & 0.000308 & 0.007108 \\
Variance & 0.00057 & 0 & 0.000065 & 0.00017 & 0 & 0.000051 \\
Skewness & -15.461 & -0.5442 & 0.00147 & -15.002 & -2.362 & 0.00061 \\
Kurtosis & 327.527 & 95.7218 & -1.46659 & 321.611 & 89.7075 & -1.02077 \\
N & 31066 & 30965 & 30965 & 26161 & 26060 & 26060 \\
Minimum & 0 & -0.00495 & -0.01 & 0 & -0.0056 & -0.01 \\
1st Quartile & 0.50349 & $-3.2 \mathrm{E}-05$ & -0.01 & 0.49755 & $-3.8 \mathrm{E}-05$ & -0.01 \\
Median & 0.50836 & $-1.6 \mathrm{E}-05$ & 0 & 0.49813 & 0.000019 & 0 \\
3rd Quartile & 0.51188 & 0.000032 & 0.01 & 0.49858 & 0.000038 & 0.01 \\
Maximum & 0.66242 & 0.004562 & 0.01 & 0.50094 & 0.004174 & 0.01 \\
\hline
\end{tabular}

Now, our observations of non-normality of the EWA parameters for the intraday return data at the NSE Nifty and BSE Sensex required to be explained along with parameters for intraday variance data. We report our results of the risk variable defined by the volatility measure of the returns LIR (MR_LIR) data for both markets in Table 6A (Table 6B), and results of the return measures SR_LIR (MCSR_LIR) data for both markets in Table 6C (Table 6D).

On the volatility measures, our results in Table 6A, illustrate that distributions are non-normal for the adaptive learning parameters, experience weight $\mathrm{N}(\mathrm{p})_{\mathrm{t}}$, the decay rate of early belief, $\phi$ and the decay rate of experience strength, $\rho$. These show the soundness of EWA method of adaptive learning such that the return and variance variables are also non-normal. The mean of strength of experience weight $\mathrm{N}(\mathrm{p})_{\mathrm{t}}$ for the variance measure (with their magnitudes of 0.51612 for the NSE data and 0.50465 for the BSE data) reflect the possibility for equal exposures of experience weights. The variances strengthen their experience weights and align trading objectives. The mean statistics of the two decay rates are very minimal and their skewness and kurtosis measures suggest for presence of non-normal distributions for the decay 
parameters in the EWA learning model. The decay rate of experience strength validates the stable nature of its non-normality.

Table 6A: Statistics of EWA Parameters and Risk Variable VLIR for NSE Nifty and BSE Sensex

\begin{tabular}{lrrrrrr}
\hline \multirow{2}{*}{ Particulars } & \multicolumn{7}{c}{ EWA Statistics for NSE Nifty } & \multicolumn{3}{c}{ EWA Statistics for BSE Sensex } \\
\cline { 2 - 7 } & $\mathbf{N}(\mathbf{p})_{\mathbf{t}}$ & $\phi_{\boldsymbol{t}}$ & $\boldsymbol{\rho}_{\boldsymbol{t}}$ & $\mathbf{N}(\mathbf{p})_{\mathbf{t}}$ & $\boldsymbol{\phi}_{\boldsymbol{t}}$ & $\boldsymbol{\rho}_{\boldsymbol{t}}$ \\
\hline A-Squared (AD & & & & & & \\
Normality Test) & 4948.37 & 5404.81 & 2413.79 & 6257.38 & 4253.75 & 2080.37 \\
$p$-Value (AD & & & & & & \\
Normality Test) & $<0.005$ & $<0.005$ & $<0.005$ & $<0.005$ & $<0.005$ & $<0.005$ \\
Mean & 0.51612 & 0 & $-1.4 \mathrm{E}-05$ & 0.50465 & 0.000019 & 0.000014 \\
StDev & 0.0239 & 0.000272 & 0.007831 & 0.05392 & 0.000287 & 0.008033 \\
Variance & 0.00057 & 0 & 0.000061 & 0.00291 & 0 & 0.000065 \\
Skewness & 9.427 & 1.0213 & 0.00248 & 6.9516 & 10.449 & -0.00256 \\
Kurtosis & 209.468 & 96.5478 & -1.36925 & 54.1751 & 179.652 & -1.45023 \\
N & 31066 & 30965 & 30965 & 26161 & 26060 & 26060 \\
Minimum & 0.31963 & -0.00419 & -0.01 & 0.48036 & -0.00111 & -0.01 \\
1st Quartile & 0.51264 & $-3.2 \mathrm{E}-05$ & -0.01 & 0.48941 & $-3.8 \mathrm{E}-05$ & -0.01 \\
Median & 0.51602 & $-1.6 \mathrm{E}-05$ & 0 & 0.49325 & $-1.9 \mathrm{E}-05$ & 0 \\
3rd Quartile & 0.52262 & 0.000032 & 0.01 & 0.50022 & 0.000038 & 0.01 \\
Maximum & 1 & 0.005048 & 0.01 & & 0.00813 & 0.01 \\
\hline
\end{tabular}

The positively skewed experience weight $N(p)_{t}$ parameter with both the stock market indices show that the variance data VLIR is moderately forward looking in the sense that the exposure of infrequent higher values of the variance measure has larger effects than those of the frequent lower values of the variance measure. That is, traders are not indifferent at gaining greater experience about the risk measure and thereby, utilising the same in trade decisions. They may enhance experience strengths about the riskiness of markets favourably and may also tune their trading gains in the two markets, and the same ranges within the minimum to maximum values of 0.42424 to 1 and 0 to 0.66667 in the NSE and BSE market respectively.

The decay rate of early attraction $\phi$ also appears to be motivating for the adaptive behavioural attribute and its average rate is about to zero while it lies within the ranges of -0.00485 to 0.00495 and -0.00467 to 0.005145 in the NSE Nifty and BSE Sensex markets respectively. The traders' earlier attractions do not die off in their memories: 
the same have dynamic and far extending effects and these are also reflected with the positively skewed leptokurtic distributions of the said decay rate.

Nonetheless, the stable non-normal decay rate of the strength of experience measure, $\rho$ with the mean values mostly about to zero and with minimum to maximum range of -0.01 and 0.01 in both the markets suggest for presence of huge market microstructure noise (MMN). Traders' adaptive behaviours have equal prospects from both ends, about the decay of the weight of experience strength. As mentioned earlier, these results also show traders' preoccupations about the adaptive, dynamic, and forward-looking earlier attraction but at robust noise about the decay in strength of experience.

Table 6B: Statistics of EWA Parameters and Risk Variable VMR_LIR for NSE Nifty and BSE Sensex

\begin{tabular}{|c|c|c|c|c|c|c|}
\hline \multirow{2}{*}{ Particulars } & \multicolumn{3}{|c|}{ EWA Statistics for NSE Nifty } & \multicolumn{3}{|c|}{ EWA Statistics for BSE Sensex } \\
\hline & $\mathbf{N}(\mathbf{p})_{t}$ & $\phi_{t}$ & $\rho_{t}$ & $\mathbf{N}(\mathbf{p})_{\mathbf{t}}$ & $\phi_{t}$ & $\rho_{t}$ \\
\hline $\begin{array}{l}\text { A-Squared (AD } \\
\text { Normality Test) }\end{array}$ & 7131.59 & 5702.98 & 2471.32 & 5581.43 & 4802.09 & 2097.15 \\
\hline $\begin{array}{l}p \text {-Value (AD } \\
\text { Normality Test) }\end{array}$ & $<0.005$ & $<0.005$ & $<0.005$ & $<0.005$ & $<0.005$ & $<0.005$ \\
\hline Mean & 0.50422 & 0.000006 & 0.000005 & 0.50688 & 0.000016 & 0.000004 \\
\hline StDev & 0.02656 & 0.000295 & 0.008031 & 0.03997 & 0.000347 & 0.00808 \\
\hline Variance & 0.00071 & 0 & 0.000065 & 0.0016 & 0 & 0.000065 \\
\hline Skewness & 15.015 & 6.129 & -0.00093 & 9.1467 & 11.211 & -0.0007 \\
\hline Kurtosis & 262.834 & 141.205 & -1.44962 & 98.345 & 207.402 & -1.46837 \\
\hline $\mathrm{N}$ & 31066 & 30965 & 30965 & 26161 & 26060 & 26060 \\
\hline Minimum & 0.39394 & -0.00353 & -0.01 & 0.48492 & -0.00172 & -0.01 \\
\hline 1st Quartile & 0.50029 & $-3.2 \mathrm{E}-05$ & -0.01 & 0.49629 & $-3.8 \mathrm{E}-05$ & -0.01 \\
\hline Median & 0.50223 & $-1.6 \mathrm{E}-05$ & 0 & 0.50016 & $-1.9 \mathrm{E}-05$ & 0 \\
\hline 3rd Quartile & 0.50412 & 0.000032 & 0.01 & 0.50451 & 0.000038 & 0.01 \\
\hline Maximum & 1 & 0.006698 & 0.01 & 1 & 0.009124 & 0.01 \\
\hline
\end{tabular}

Table 6B illusrates that the variance for mean returns (VMR_LIR) reflects distributions of the EWA parameters viz., experience weight $N(p)_{t}$, decay of early belief $\phi$ and decay of experience strength $\rho$ are non-normal. The distributions of experience weight $\mathrm{N}(\mathrm{p})_{\mathrm{t}}$ and decay of early belief are positively skewed and leptokurtic while that for decay of experience strength is low, negatively skewed and platykurtic. These results show soundness of the hypothesised dynamic nature of the 
EWA method of adaptive learning. The three quartiles of the strength of experience weight (those are mostly equal to half) read along with the skewness and kurtosis measures show presence of huge MMN. The decay rates are minimal and these confirm stable non-normal distribution for the EWA parameter.

Table 6C: Statistics of EWA Parameters and Risk Variable VSR_LIR for NSE Nifty and BSE Sensex

\begin{tabular}{lrrrrrr}
\hline \multirow{2}{*}{ Particulars } & \multicolumn{7}{c}{ EWA Statistics for NSE Nifty } & EWA Statistics for BSE Sensex \\
\cline { 2 - 7 } & $\mathbf{N}(\mathbf{p})_{\mathbf{t}}$ & \multicolumn{1}{c}{$\boldsymbol{\phi}_{\boldsymbol{t}}$} & $\boldsymbol{\rho}_{\boldsymbol{t}}$ & $\mathbf{N}(\mathbf{p})_{\mathbf{t}}$ & $\boldsymbol{\phi}_{\mathbf{t}}$ & $\boldsymbol{\rho}_{\boldsymbol{t}}$ \\
\hline A-Squared (AD & & & & & & \\
Normality Test) & 7745.98 & 5616.05 & 2433.04 & 4142.59 & 4328.57 & 2103.62 \\
$p$-Value (AD & & & & & & \\
Normality Test) & $<0.005$ & $<0.005$ & $<0.005$ & $<0.005$ & $<0.005$ & $<0.005$ \\
Mean & 0.49464 & 0.000012 & 0.000028 & 0.49895 & 0.000003 & 0.000015 \\
StDev & 0.037 & 0.000287 & 0.007916 & 0.03145 & 0.000301 & 0.008097 \\
Variance & 0.00137 & 0 & 0.000063 & 0.00099 & 0 & 0.000066 \\
Skewness & 9.315 & 11.236 & -0.00493 & 9.586 & 2.8546 & -0.00273 \\
Kurtosis & 100.121 & 232.699 & -1.40403 & 158.82 & 91.9388 & -1.47473 \\
N & 31066 & 30965 & 30965 & 26161 & 26060 & 26060 \\
Minimum & 0.4771 & -0.00187 & -0.01 & 0.31282 & -0.00405 & -0.01 \\
1st Quartile & 0.48602 & $-3.2 \mathrm{E}-05$ & -0.01 & 0.49749 & $-3.8 \mathrm{E}-05$ & -0.01 \\
Median & 0.48959 & 0.000016 & 0 & 0.50183 & 0.000019 & 0 \\
3rd Quartile & 0.49242 & 0.000032 & 0.01 & 0.50627 & 0.000038 & 0.01 \\
Maximum & 1 & 0.007923 & 0.01 & & 0.00563 & 0.01 \\
\hline
\end{tabular}

Results in Table 6C in the above with the risk measures VSR_LIR for the return data SR_LIR, and the same in Table 6D illustrated below, with the risk measure VMCSR_LIR for the return data MCSR_LIR also confirm the non-normality nature of distributions for the three adaptive learning parameters (viz., $\mathrm{N}(\mathrm{p})_{\mathrm{t}}, \phi_{t}$, and $\rho_{t}$ ). These observations show that the non-normality nature of the distributions is a persistent evidence and any repetitive discussion is avoided to save space.

Now, let us explore distributional properties of the EWA statistics for the higher order moments viz., at skewness and kurtosis measures of returns data. In Table 7A, the EWA model statistics for the skewness measure of LIR returns confirm nonnormality about their distributions. These illustrate non-normality in terms of skewness and kurtosis measures of the skewness parameter (Pearson, 1905). Their tails mostly determine the kurtosis of distributions (Westfall, 2014). This finding 
shows noise and adaptive dynamics in learning choices. In either of the two markets, traders' strength of experience weight is mostly half and equally likely. There is also information asymmetry at strength experiences. The skewness measure of the decay rate of early attraction also shows adaptive behavioural attribute such that these involve lower ranges viz., -0.0034 to 0.005968 and -0.00577 to 0.003689 in the NSE and BSE markets respectively while distributions are positively skewed and leptokurtic in nature. The decay rates of experience strength are minimal, stable, platykurtic, and non-normal. The earlier attractions do not die off but live with noise. The decay rates of early attractions show higher heterogeneity while the experience decay is mostly homogeneous and symmetric.

Table 6D: Statistics of EWA Parameters and Risk Variable VMCSR_LIR for NSE Nifty and BSE Sensex

\begin{tabular}{lrrrrrr}
\hline \multirow{2}{*}{ Particulars } & \multicolumn{7}{c}{ EWA Statistics for NSE Nifty } & \multicolumn{3}{c}{ EWA Statistics for BSE Sensex } \\
\cline { 2 - 7 } & $\mathbf{N}(\mathbf{p})_{\mathbf{t}}$ & \multicolumn{1}{c}{$\boldsymbol{\phi}_{\boldsymbol{t}}$} & $\boldsymbol{\rho}_{\boldsymbol{t}}$ & $\mathbf{N}(\mathbf{p})_{\mathbf{t}}$ & $\boldsymbol{\phi}_{\boldsymbol{t}}$ & $\boldsymbol{\rho}_{\boldsymbol{t}}$ \\
\hline A-Squared (AD & & & & & & \\
Normality Test) & 6962.28 & 5846.62 & 2457.78 & 4683.17 & 4360.26 & 2094.59 \\
$p$-Value (AD & & & & & & \\
Normality Test) & $<0.005$ & $<0.005$ & $<0.005$ & $<0.005$ & $<0.005$ & $<0.005$ \\
Mean & 0.51497 & 0.000013 & 0.000025 & 0.51392 & 0.000003 & 0.000015 \\
StDev & 0.03698 & 0.000304 & 0.007995 & 0.02795 & 0.000304 & 0.008073 \\
Variance & 0.00137 & 0 & 0.000064 & 0.00078 & 0 & 0.000065 \\
Skewness & 8.7307 & 12.59 & -0.00441 & 12.935 & 2.6576 & -0.00272 \\
Kurtosis & 91.4148 & 265.526 & -1.43549 & 224.348 & 90.9244 & -1.46575 \\
N & 31066 & 30965 & 30965 & 26161 & 26060 & 26060 \\
Minimum & 0.48232 & -0.00158 & -0.01 & 0.33161 & -0.00408 & -0.01 \\
1st Quartile & 0.50556 & $-3.2 \mathrm{E}-05$ & -0.01 & 0.5071 & $-3.8 \mathrm{E}-05$ & -0.01 \\
Median & 0.50829 & $-1.6 \mathrm{E}-05$ & 0 & 0.51276 & $-1.9 \mathrm{E}-05$ & 0 \\
3rd Quartile & 0.51092 & 0.000032 & 0.01 & 0.51959 & 0.000038 & 0.01 \\
Maximum & & 0.008715 & 0.01 & & 0.00563 & 0.01 \\
\hline
\end{tabular}

Table 7A: Statistics of EWA Parameters and Skewness Variable SKLIR for NSE Nifty and BSE Sensex

\begin{tabular}{|c|c|c|c|c|c|c|}
\hline \multirow{2}{*}{ Particulars } & \multicolumn{3}{|c|}{ EWA Statistics for NSE Nifty } & \multicolumn{3}{|c|}{ EWA Statistics for BSE Sensex } \\
\hline & $\mathbf{N}(\mathbf{p})_{\mathbf{t}}$ & $\phi_{t}$ & $\rho t$ & $\mathbf{N}(\mathbf{p})_{t}$ & $\phi_{t}$ & $\rho t$ \\
\hline $\begin{array}{l}\text { A-Squared (AD } \\
\text { Normality Test) }\end{array}$ & 6735.16 & 5564.94 & 2485.63 & 5155.07 & 4421.67 & 2159.27 \\
\hline
\end{tabular}




\begin{tabular}{lrrrrrr}
\hline \multirow{2}{*}{ Particulars } & \multicolumn{7}{c}{ EWA Statistics for NSE Nifty } & \multicolumn{4}{c}{ EWA Statistics for BSE Sensex } \\
\cline { 2 - 7 } & $\mathbf{N}(\mathbf{p}) \mathbf{t}$ & $\boldsymbol{\phi} \boldsymbol{t}$ & $\boldsymbol{\rho} \boldsymbol{t}$ & $\mathbf{N}(\mathbf{p}) \mathbf{t}$ & $\boldsymbol{\phi}_{\boldsymbol{t}}$ & $\boldsymbol{\rho} \boldsymbol{t}$ \\
\hline p-Value (AD & & & & & & \\
Normality Test) & $<0.005$ & $<0.005$ & $<0.005$ & $<0.005$ & $<0.005$ & $<0.005$ \\
Mean & 0.49656 & 0.000005 & $-2 \mathrm{E}-06$ & 0.49931 & $-5 \mathrm{E}-06$ & 0.000002 \\
StDev & 0.018 & 0.000284 & 0.008066 & 0.01732 & 0.00031 & 0.008221 \\
Variance & 0.00032 & 0 & 0.000065 & 0.0003 & 0 & 0.000068 \\
Skewness & -14.02 & 5.053 & 0.00029 & 15.473 & -3.8242 & -0.00035 \\
Kurtosis & 418.768 & 119.566 & -1.46294 & 480.548 & 95.2018 & -1.52047 \\
N & 31066 & 30965 & 30965 & 26161 & 26060 & 26060 \\
Minimum & 0 & -0.0034 & -0.01 & 0.31429 & -0.00577 & -0.01 \\
1st Quartile & 0.49532 & $-3.2 \mathrm{E}-05$ & -0.01 & 0.49749 & $-3.8 \mathrm{E}-05$ & -0.01 \\
Median & 0.4975 & 0.000016 & 0 & 0.50016 & $-1.9 \mathrm{E}-05$ & 0 \\
3rd Quartile & 0.49916 & 0.000032 & 0.01 & 0.50163 & 0.000038 & 0.01 \\
Maximum & 0.69828 & 0.005968 & 0.01 & 1 & 0.003689 & 0.01 \\
\hline
\end{tabular}

In Tables 7B, 7C and 7D, we explore the distributional properties of the EWA statistics for skewness measures at alternative return definitions. We show that the behavioural distributions of the skewness statistics of returns are non-normal. In these cases, the EWA parameters show dynamism and noise. The mean strengths of their respective experience weights are approximately equal to half. That is, traders are exposed to information asymmetry in strengthening their experiences. The respective decay rates are regular as observed in Table 7A. These suggest for noise dynamics for decay rate in early attractions while that for decay rate in experience strength is stable but both are non-normal in terms of distributions. The decay rate of early exposure is highly heterogeneous while that of the experience decay is mostly homogeneous and symmetric. It is observed enthusiastically that magnitudes of the kurtosis measure for the decay rate of strength of experience and those for the alternative definitions of skewness are mostly negative or about to -1.5 .

Table 7B: Statistics of EWA Parameters and Skewness Variable SKMR_LIR for NSE Nifty and BSE Sensex

\begin{tabular}{|c|c|c|c|c|c|c|}
\hline \multirow{2}{*}{ Particulars } & \multicolumn{3}{|c|}{ EWA Statistics for NSE Nifty } & \multicolumn{3}{|c|}{ EWA Statistics for BSE Sensex } \\
\hline & $\mathbf{N}(\mathbf{p})_{t}$ & $\phi_{t}$ & $\rho t$ & $\mathbf{N}(\mathbf{p})_{t}$ & $\phi_{t}$ & $\rho t$ \\
\hline $\begin{array}{l}\text { A-Squared (AD } \\
\text { Normality Test) }\end{array}$ & 6438.91 & 5601.13 & 2511.5 & 5001.83 & 4386.83 & 2105.47 \\
\hline
\end{tabular}




\begin{tabular}{|c|c|c|c|c|c|c|}
\hline \multirow{2}{*}{ Particulars } & \multicolumn{3}{|c|}{ EWA Statistics for NSE Nifty } & \multicolumn{3}{|c|}{ EWA Statistics for BSE Sensex } \\
\hline & $\mathbf{N}(\mathbf{p})_{\mathbf{t}}$ & $\phi_{t}$ & $\rho t$ & $\mathbf{N}(\mathbf{p})_{\mathbf{t}}$ & $\phi_{t}$ & $\rho_{t}$ \\
\hline $\begin{array}{l}p \text {-Value (AD } \\
\text { Normality Test) }\end{array}$ & $<0.005$ & $<0.005$ & $<0.005$ & $<0.005$ & $<0.005$ & $<0.005$ \\
\hline Mean & 0.49425 & $-6 \mathrm{E}-06$ & $-1.1 \mathrm{E}-05$ & 0.50742 & 0.000002 & 0.000003 \\
\hline StDev & 0.01645 & 0.000286 & 0.008122 & 0.01695 & 0.000307 & 0.008102 \\
\hline Variance & 0.00027 & 0 & 0.000066 & 0.00029 & 0 & 0.000066 \\
\hline Skewness & -6.139 & -5.962 & 0.00201 & -19.51 & 2.0805 & -0.00049 \\
\hline Kurtosis & 234.038 & 140.552 & -1.48408 & 577.667 & 87.3258 & -1.47652 \\
\hline $\mathrm{N}$ & 31066 & 30965 & 30965 & 26161 & 26060 & 26060 \\
\hline Minimum & 0 & -0.0066 & -0.01 & 0 & -0.00427 & -0.01 \\
\hline 1st Quartile & 0.49594 & $-3.2 \mathrm{E}-05$ & -0.01 & 0.50509 & $-3.8 \mathrm{E}-05$ & -0.01 \\
\hline Median & 0.49729 & 0.000016 & 0 & 0.50639 & $-1.9 \mathrm{E}-05$ & 0 \\
\hline 3rd Quartile & 0.49812 & 0.000032 & 0.01 & 0.50991 & 0.000038 & 0.01 \\
\hline Maximum & 0.8125 & 0.003493 & 0.01 & 0.69091 & 0.005437 & 0.01 \\
\hline
\end{tabular}

Table 7C: Statistics of EWA Parameters and Skewness Variable SKSR_LIR for NSE Nifty and BSE Sensex

\begin{tabular}{lrrrrrr}
\hline \multirow{2}{*}{ Particulars } & \multicolumn{7}{c}{ EWA Statistics for NSE Nifty } & \multicolumn{4}{c}{ EWA Statistics for BSE Sensex } \\
\cline { 2 - 7 } & $\mathbf{N}(\mathbf{p})_{\mathbf{t}}$ & \multicolumn{1}{c}{$\boldsymbol{\phi}_{\boldsymbol{t}}$} & $\boldsymbol{\rho}_{\boldsymbol{t}}$ & $\mathbf{N}(\mathbf{p})_{\mathbf{t}}$ & $\boldsymbol{\phi}_{\boldsymbol{t}}$ & $\boldsymbol{\rho}_{\boldsymbol{t}}$ \\
\hline A-Squared (AD & & & & & & \\
Normality Test) & 5924.02 & 5390.81 & 2473.55 & 4450.78 & 4428.43 & 2127.04 \\
$p$-Value (AD & & & & & & \\
Normality Test) & $<0.005$ & $<0.005$ & $<0.005$ & $<0.005$ & $<0.005$ & $<0.005$ \\
Mean & 0.50598 & 0.000005 & $-5 \mathrm{E}-06$ & 0.4975 & $-4 \mathrm{E}-06$ & $-4 \mathrm{E}-06$ \\
StDev & 0.02325 & 0.000272 & 0.008037 & 0.01732 & 0.00031 & 0.008153 \\
Variance & 0.00054 & 0 & 0.000065 & 0.0003 & 0 & 0.000066 \\
Skewness & -9.143 & 4.668 & 0.00093 & -17.786 & -3.5854 & 0.00077 \\
Kurtosis & 251.716 & 113.534 & -1.45179 & 463.26 & 96.7318 & -1.4957 \\
N & 31066 & 30965 & 30965 & 26161 & 26060 & 26060 \\
Minimum & 0 & -0.00349 & -0.01 & 0 & -0.00602 & -0.01 \\
1st Quartile & 0.50202 & $-3.2 \mathrm{E}-05$ & -0.01 & 0.4955 & $-3.8 \mathrm{E}-05$ & -0.01 \\
Median & 0.50461 & 0.000016 & 0 & 0.49787 & 0.000019 & 0 \\
3rd Quartile & 0.50855 & 0.000032 & 0.01 & 0.50057 & 0.000038 & 0.01 \\
Maximum & 0.71429 & 0.005624 & 0.01 & 0.57273 & 0.003827 & 0.01 \\
\hline
\end{tabular}


Table 7D: Statistics of EWA Parameters and Skewness Variable SKMCSR_LIR for NSE Nifty and BSE Sensex

\begin{tabular}{lrrrrrr}
\hline \multirow{2}{*}{ Particulars } & \multicolumn{3}{c}{ EWA Statistics for NSE Nifty } & \multicolumn{4}{c}{ EWA Statistics for BSE Sensex } \\
\cline { 2 - 7 } & $\mathbf{N}(\mathbf{p}) \mathbf{t}$ & $\boldsymbol{\phi}_{\boldsymbol{t}}$ & $\boldsymbol{\rho} \boldsymbol{t}$ & $\mathbf{N}(\mathbf{p}) \mathbf{t}$ & $\boldsymbol{\phi}_{\boldsymbol{t}}$ & $\boldsymbol{\rho} \boldsymbol{t}$ \\
\hline A-Squared (AD & 6133.39 & 5551.3 & 2502.39 & 6017.96 & 4431.58 & 2119.16 \\
$\begin{array}{l}\text { Normalitv Test) } \\
p \text {-Value (AD }\end{array}$ & & & & & & \\
Normality Test) & $<0.005$ & $<0.005$ & $<0.005$ & $<0.005$ & $<0.005$ & $<0.005$ \\
Mean & 0.4988 & $-3 \mathrm{E}-06$ & $-7 \mathrm{E}-06$ & 0.50173 & $-4 \mathrm{E}-06$ & $-2 \mathrm{E}-06$ \\
StDev & 0.01271 & 0.000283 & 0.008103 & 0.02176 & 0.000311 & 0.008135 \\
Variance & 0.00016 & 0 & 0.000066 & 0.00047 & 0 & 0.000066 \\
Skewness & -4.539 & -2.921 & 0.00135 & -17.318 & -2.9875 & 0.00028 \\
Kurtosis & 570.592 & 110.899 & -1.477 & 374.788 & 94.9325 & -1.48898 \\
N & 31066 & 30965 & 30965 & 26161 & 26060 & 26060 \\
Minimum & 0 & -0.00573 & -0.01 & 0 & -0.00582 & -0.01 \\
1st Quartile & 0.49747 & $-3.2 \mathrm{E}-05$ & -0.01 & 0.49995 & $-3.8 \mathrm{E}-05$ & -0.01 \\
Median & 0.49871 & 0.000016 & 0 & 0.50115 & $-1.9 \mathrm{E}-05$ & 0 \\
3rd Quartile & 0.50051 & 0.000032 & 0.01 & 0.50278 & 0.000038 & 0.01 \\
Maximum & 0.83333 & 0.004177 & 0.01 & 0.57669 & 0.00411 & 0.01 \\
\hline
\end{tabular}

Let us now discuss the results of EWA model statistics for the kurtosis parameters with reference to the the four return definitions. The results in Table 8A for the EWA model statistics $\phi, \rho$, and $\mathrm{N}(\mathrm{p})_{\mathrm{t}}$ show that the behavioural distributions of the statistics are non-normal and robust. The mean values of the strength of experience weight for the NSE Nifty data as well as the BSE Sensex data re in parity with the stated findings for the different definitions of returns, variance, and skewness measures. Traders' exposures are mostly equal to half towards experience weight parameter and there is inbuilt heterogeneity in the different strata groups in markets. The decay rate for early attraction $\phi$ is also positively skewed, leptokurtic, and non-normal in distributions. This reveals heterogeneity and information asymmetry. The decay rate of experience strength $\rho$ is homogeneous and platykurtic with little asymmetry in information. These observations with kurtosis measures confirm the presence of Market Microstructure Noise in intraday trade data. The said noise is pervasive and persistent in the markets. In Tables $8 \mathrm{~B}, 8 \mathrm{C}$ and $8 \mathrm{D}$, results with reference to the other return definitions also validate these findings. 
Table 8A: Statistics of EWA Parameters and Kurtosis Variable KTLIR for NSE Nifty and BSE Sensex

\begin{tabular}{|c|c|c|c|c|c|c|}
\hline \multirow{2}{*}{ Particulars } & \multicolumn{3}{|c|}{ EWA Statistics for NSE Nifty } & \multicolumn{3}{|c|}{ EWA Statistics for BSE Sensex } \\
\hline & $\mathbf{N}(\mathbf{p})_{\mathbf{t}}$ & $\phi_{t}$ & $\rho_{t}$ & $\mathbf{N}(\mathbf{p})_{\mathbf{t}}$ & $\phi_{t}$ & $\rho_{t}$ \\
\hline $\begin{array}{l}\text { A-Squared (AD } \\
\text { Normality Test) }\end{array}$ & 6110.56 & 5650.28 & 2458.98 & 6257.38 & 4253.75 & 2080.37 \\
\hline $\begin{array}{l}p \text {-Value (AD } \\
\text { Normality Test) }\end{array}$ & $<0.005$ & $<0.005$ & $<0.005$ & $<0.005$ & $<0.005$ & $<0.005$ \\
\hline Mean & 0.49827 & 0.000006 & 0.00001 & 0.50465 & 0.000019 & 0.000014 \\
\hline StDev & 0.02206 & 0.000291 & 0.007998 & 0.05392 & 0.000287 & 0.008033 \\
\hline Variance & 0.00049 & 0 & 0.000064 & 0.00291 & 0 & 0.000065 \\
\hline Skewness & 14.696 & 5.898 & -0.0018 & 6.9516 & 10.449 & -0.00256 \\
\hline Kurtosis & 290.05 & 140.865 & -1.43686 & 54.1751 & 179.652 & -1.45023 \\
\hline $\mathrm{N}$ & 31066 & 30965 & 30965 & 26161 & 26060 & 26060 \\
\hline Minimum & 0.45521 & -0.00364 & -0.01 & 0.48036 & -0.00111 & -0.01 \\
\hline $1^{\text {st }}$ Quartile & 0.49311 & $-3.2 \mathrm{E}-05$ & -0.01 & 0.48941 & $-3.8 \mathrm{E}-05$ & -0.01 \\
\hline Median & 0.49593 & $-1.6 \mathrm{E}-05$ & 0 & 0.49325 & $-1.9 \mathrm{E}-05$ & 0 \\
\hline $3^{\text {rd }}$ Quartile & 0.50041 & 0.000032 & 0.01 & 0.50022 & 0.000038 & 0.01 \\
\hline Maximum & 1 & 0.006601 & 0.01 & 1 & 0.00813 & 0.01 \\
\hline
\end{tabular}

Table 8B: Statistics of EWA Parameters and Kurtosis Variable KTMR_LIR for NSE Nifty and BSE Sensex

\begin{tabular}{lrrrrrr}
\hline \multirow{2}{*}{ Particulars } & \multicolumn{7}{c}{ EWA Statistics for NSE Nifty } & \multicolumn{3}{c}{ EWA Statistics for BSE Sensex } \\
\cline { 2 - 7 } & $\mathbf{N}(\mathbf{p})_{\mathbf{t}}$ & \multicolumn{1}{c}{$\phi_{\boldsymbol{t}}$} & $\boldsymbol{\rho}_{\boldsymbol{t}}$ & $\mathbf{N}(\mathbf{p})_{\mathbf{t}}$ & $\boldsymbol{\phi}_{\boldsymbol{t}}$ & $\boldsymbol{\rho}_{\boldsymbol{t}}$ \\
\hline A-Squared (AD & & & & & & \\
Normality Test) & 9034.39 & 5882.01 & 2498.77 & 5649.78 & 4467.03 & 2124.35 \\
$p$-Value (AD & & & & & & \\
Normality Test) & $<0.005$ & $<0.005$ & $<0.005$ & $<0.005$ & $<0.005$ & $<0.005$ \\
Mean & 0.49589 & $-1.1 \mathrm{E}-05$ & $-1.4 \mathrm{E}-05$ & 0.50267 & 0.000006 & 0.000013 \\
StDev & 0.029 & 0.000307 & 0.008095 & 0.01956 & 0.000315 & 0.008147 \\
Variance & 0.00084 & 0 & 0.000066 & 0.00038 & 0 & 0.000066 \\
Skewness & -11.781 & -10.517 & 0.00259 & 3.945 & 4.505 & -0.00232 \\
Kurtosis & 157 & 207.745 & -1.47406 & 217.395 & 108.172 & -1.49343 \\
N & 31066 & 30965 & 30965 & 26161 & 26060 & 26060 \\
Minimum & 0 & -0.00796 & -0.01 & 0 & -0.00373 & -0.01 \\
$1^{\text {st } \text { Quartile }}$ & 0.4979 & $-3.2 \mathrm{E}-05$ & -0.01 & 0.49802 & $-3.8 \mathrm{E}-05$ & -0.01 \\
\hline
\end{tabular}




\begin{tabular}{lrrrrrr}
\hline \multirow{2}{*}{ Particulars } & \multicolumn{3}{c}{ EWA Statistics for NSE Nifty } & \multicolumn{3}{c}{ EWA Statistics for BSE Sensex } \\
\cline { 2 - 7 } & $\mathbf{N}(\mathbf{p})_{\mathbf{t}}$ & $\boldsymbol{\phi}_{\boldsymbol{t}}$ & $\boldsymbol{\rho} \boldsymbol{t}$ & $\mathbf{N}(\mathbf{p})_{\mathbf{t}}$ & $\boldsymbol{\phi}_{\boldsymbol{t}}$ & $\boldsymbol{\rho} \boldsymbol{t}$ \\
\hline Median & 0.49979 & $-1.6 \mathrm{E}-05$ & 0 & 0.49951 & 0.000019 & 0 \\
$3^{\text {rd }}$ Quartile & 0.50101 & 0.000032 & 0.01 & 0.50193 & 0.000038 & 0.01 \\
Maximum & 0.51206 & 0.002032 & 0.01 & 0.875 & 0.006309 & 0.01 \\
\hline
\end{tabular}

Table 8C: Statistics of EWA Parameters and Kurtosis Variable KTSR_LIR for NSE Nifty and BSE Sensex

\begin{tabular}{lrrrrrr}
\hline \multirow{2}{*}{ Particulars } & \multicolumn{7}{c}{ EWA Statistics for NSE Nifty } & \multicolumn{4}{c}{ EWA Statistics for BSE Sensex } \\
\cline { 2 - 7 } & $\mathbf{N}(\mathbf{p})_{\mathbf{t}}$ & $\phi_{t}$ & $\boldsymbol{\rho}_{\boldsymbol{t}}$ & $\mathbf{N}(\mathbf{p})_{\mathbf{t}}$ & $\phi_{\boldsymbol{t}}$ & $\boldsymbol{\rho}_{\boldsymbol{t}}$ \\
\hline A-Squared (AD & & & & & & \\
Normality Test) & 5139.5 & 5469.77 & 2491.15 & 5608.34 & 4377.71 & 2124.55 \\
$p$-Value (AD & & & & & & \\
Normality Test) & $<0.005$ & $<0.005$ & $<0.005$ & $<0.005$ & $<0.005$ & $<0.005$ \\
Mean & 0.50572 & 0.000003 & 0.000006 & 0.50899 & 0.000001 & 0.000009 \\
StDev & 0.02418 & 0.000277 & 0.008079 & 0.02129 & 0.000306 & 0.008148 \\
Variance & 0.00058 & 0 & 0.000065 & 0.00045 & 0 & 0.000066 \\
Skewness & 11.311 & 2.606 & -0.00117 & 18.403 & 1.1432 & -0.00162 \\
Kurtosis & 193.326 & 114.581 & -1.46773 & 404.507 & 84.9145 & -1.49361 \\
N & 31066 & 30965 & 30965 & 26161 & 26060 & 26060 \\
Minimum & 0.44961 & -0.00423 & -0.01 & 0.40602 & -0.00443 & -0.01 \\
$1^{\text {st }}$ Quartile & 0.49717 & $-3.2 \mathrm{E}-05$ & -0.01 & 0.50413 & $-3.8 \mathrm{E}-05$ & -0.01 \\
Median & 0.49962 & 0.000016 & 0 & 0.506 & $-1.9 \mathrm{E}-05$ & 0 \\
$3^{\text {rd }}$ Quartile & 0.50631 & 0.000032 & 0.01 & 0.50895 & 0.000038 & 0.01 \\
Maximum & 1 & 0.00563 & 0.01 & & 0.005242 & 0.01 \\
\hline
\end{tabular}

Even though the EWA statistics are nearly repetitive in nature in all Tables, these are read here as confirmative and robust. In other words, irrespective of differences in their definitions , be it the log index price relatives $\left(\mathrm{LIR}_{\mathrm{t}}\right)$, the mean return $\left(M R \_L I R+\right.$ ), the standardised returns (SR_LIR), or the mean controlled standardised returns (MCSR_LIR), the EWA statistics show market microstructure noise at the intraday market data of the NSE Nifty and BSE Sensex. In the next section, we discuss the general findings on the MMN. We offer conceptual generalisation along with structural generalisation with Figures 1and 2 in Appendices 3 and 4 for parameters of the BSE Sensex (NSE Nifty) returns, variances, skewness and kurtosis measures. We also generalise observations for the EWA statistics along with for the BSE and NSE market data respectively for the different definitions of returns, 
variances, skewness and kurtosis measures and to save space, the relevant Figures, are not attached here but can be produced on demand.

Table 8D: Statistics of EWA Parameters and Kurtosis Variable KTMCSR_LIR for NSE Nifty and BSE Sensex

\begin{tabular}{lrrrrrr}
\hline \multirow{2}{*}{ Particulars } & \multicolumn{7}{c}{ EWA Statistics for NSE Nifty } & EWA Statistics for BSE Sensex \\
\cline { 2 - 7 } & $\mathbf{N}(\mathbf{p})_{\mathbf{t}}$ & \multicolumn{1}{c}{$\boldsymbol{\phi}_{\boldsymbol{t}}$} & $\boldsymbol{\rho}_{\boldsymbol{t}}$ & $\mathbf{N}(\mathbf{p})_{\mathbf{t}}$ & $\boldsymbol{\phi}_{\boldsymbol{t}}$ & $\boldsymbol{\rho}_{\boldsymbol{t}}$ \\
\hline A-Squared (AD & & & & & & \\
Normality Test) & 7364.09 & 5893.35 & 2507.34 & 5549.82 & 4446.25 & 2117.37 \\
$p$-Value (AD & & & & & & \\
Normality Test) & $<0.005$ & $<0.005$ & $<0.005$ & $<0.005$ & $<0.005$ & $<0.005$ \\
Mean & 0.49862 & -0.00001 & $-1.8 \mathrm{E}-05$ & 0.49616 & 0.000005 & 0.000017 \\
StDev & 0.02453 & 0.000309 & 0.008113 & 0.02278 & 0.000313 & 0.008131 \\
Variance & 0.0006 & 0 & 0.000066 & 0.00052 & 0 & 0.000066 \\
Skewness & -11.71 & -9.88 & 0.00336 & 9.821 & 4.233 & -0.00309 \\
Kurtosis & 168.7 & 198.095 & -1.48087 & 149.254 & 105.754 & -1.48739 \\
N & 31066 & 30965 & 30965 & 26161 & 26060 & 26060 \\
Minimum & 0 & -0.00794 & -0.01 & 0 & -0.00379 & -0.01 \\
1st Quartile & 0.50099 & $-3.2 \mathrm{E}-05$ & -0.01 & 0.49 & $-3.8 \mathrm{E}-05$ & -0.01 \\
Median & 0.50252 & $-1.6 \mathrm{E}-05$ & 0 & 0.49331 & 0.000019 & 0 \\
3rd Quartile & 0.50427 & 0.000032 & 0.01 & 0.49573 & 0.000038 & 0.01 \\
Maximum & 0.51467 & 0.002338 & 0.01 & 0.94737 & 0.006212 & 0.01 \\
\hline & & & & & &
\end{tabular}

\section{Generalisation of Findings}

We have found that the intraday stock market returns are non-normal. It has been revealed that the market microstructure noise is robustly present in the market returns. Results are discussed for conceptual and structural generalisations. These involve treatment applicability at different circumstances, measurement applicability at different sample groups, and size applicability at larger size random samples (Runkel \& McGrath, 1972; Firestone, 1993).

The graphical presentations of the AD Test, for the BSE market returns viz., the Log of Index relatives LIR in Figure1, shows that the dotted graph of probability plot of LIR data lies significantly far away from the straight normality plot with the AD value -161.991 at $\mathrm{p}<0.005$ while the AD values for MR_LIR, SR_LIR, and MCSR_LIR are respectively 118.143, 231.046 and 779.442. Once we move over the Figure1, it can be found that the AD values for the variance of the BSE market returns 
data, VLIR, the skewness of the same SKLIR, and the kurtosis, KTLIR are 178.924, 20.747 , and 500.617 at $p$ values less than 0.005 . These findings suggest that in terms of treatment applicability, the stock market returns and MMN are non-normal in their distributions. The other AD values and probability plots for the variance, skewness, and kurtosis measures in Figure 1 confirm consistency at the presence of noise in the BSE market returns. Similar observations in Figure 2 suggest that the present research passes the measurement applicability test for generalisation. The study applies to the size of 26060 (30965) 1D timestamp real time population data for the BSE Sensex (NSE Nifty) index. These include the most of the retrievable 1D trading data from the online trading system in the BSE and NSE stock markets. The generalisation property of size applicability suggests the population data size $(>10,000)$ is enough to generalise the observations and any enhancement of data size would not significantly increase its generalisability (Firestone, 1993). The NSE Nifty and BSE Sensex market returns and the MMN are non-normal in their distributions and results are generalisable.

In the EWA learning model, traders have some initial attraction level and the same is reinforced at levels of experience strength. Initial attraction may be enhanced or fade away. A persistent (noisy) decay rate of initial attraction could track persistency (noisy) behaviour of the trader in their trading. A persistent decay rate in initial attraction would deter intraday traders for further trading and would reduce the market microstructure noise in the market while a noisy and non-stationary decay rate will find impetus for intraday noise traders. The intraday traders' adverse (favourable) intraday trading experience in the stock markets could provide negative (positive) reinforcements and thereby, these induce positive (negative) magnitudes for the decay rate in experience strength.

Observations suggest that the mean probability of experience strength is approximately half $(0.5)$ and the same has exposure to greater limits of the variables under considerations viz., returns data of alternative definitions, their respective variance data, the relevant skewness and kurtosis data. The mean value of the probability of intraday traders' experience strength is non-normal, erratic and unstable. Conceptually, the distribution of the experience strength with an approximately equal mean probability (i.e., of $1 / 2$ ) is comparable to a biased coin with an approximate probability of half (i.e., $1 / 2$ ) for its head or tail (but not certainly equal to $1 / 2$ ) with its biases arising from the environment where it is tossed but not when it is tossed. The intraday traders could make their experience strength favourable to them for trading and the environment itself has forces to disproportionate the same. In addition to the above generalisation, findings about the decay rate of early 
attractions suggest that the decay rate is minimal, non-normal and erratic in its nature. That is, intraday stock traders' early attraction persists. They experience least demotivation towards their initial attractions and hence, they could easily be indulged in trading by the pervasive noise in their early attraction parameters.

Furthermore, the decay rate of experience strength of the intraday traders suggests that the concerned decay rate has $1 \%$ of chances of motivation to be inspired or despaired with its mean at zero. Environments of the game at its biased equal probability for experience strength, at minimal decay rate of early attraction and at low threat in terms of the decay rate of experience strength, make the adaptive EWA learning model stable, persistent and dynamic in explaining the adaptive experience weighted attraction behaviour of intraday traders. These findings are consistent across the two markets, the BSE Sensex and NSE Nifty, for the different variables representing the relevant return definitions, variances, and the skewness and kurtosis measures. The EWA model is applied for the full range of the population data of the two stock markets. The findings of the model parameters are generalisable. In precise, the adaptive EWA learning behaviours model could explain the pervasive presence of noise that is being arising from the noisy behaviours of intraday traders in the markets.

Given such pervasive presence of noise at intraday trading in Indian stock markets, a proper methodological advancement is cautiously needed by intraday traders before they leap up for intraday trading in the markets. In a very simple approach along with the methodology of Camerer and Ho (1999), the present study has just explored the extents of possibility of quantifying the chance factors for the parameters of the EWA learning method.

\section{Conclusion}

With the motivation from the chaos theory in neoclassical finance, we have set forth to experience intraday traders' 'inner chaos' along with markets' 'outer chaos'. We have considered the behavioural finance approach rather than the neoclassical one. Further, the stock market indices are assumed to incorporate the aggregate chaos, both inner and outer. We have called this aggregate chaos as the MMN. Such chaos or noise shows the aggregate market sentiments.

Contemporary studies in Financial Economics with daily trading data show that the stock market returns are non-normal and explain the same with the standard finance arguments. They make suggestions for information efficiency and heteroskedasticity at correlated variance. In equilibrium, markets are professed to be 
informed and fair. On the contrary, we have showed that the stocks' prices in the markets move at persistence presence of noise at intraday trading data. The stock market indices contain the MMN and the intraday stock market returns exhibit such noises.

In exploring MMN, we have put forth the research query if the intraday market returns in the NSE and BSE markets are normal and stable in their theoretical distributions. In addition, we have applied the experience weighted attraction (EWA) learning approach of Camerer and Ho (1999) for the intraday traders in stock markets. We have examined three behavioural parameters of the approach and have explored whether the traders' experience strength during intraday trading and the decay rates for early attraction and experience strength could explain MMN or not. We have empirically showed that the NSE Nifty and BSE Sensex market returns are erratic, noisy and non-normal in distributions.

In brief, the intraday BSE Sensex and NSE Nifty stock market returns, if measured at the $\log$ of index relatives or its averages, are approximately with zero mean and zero variance but skewed and leptokurtic. In other words, there is 'no risk - no return - huge inclinations - large prospects'. This green-signal appears dejected with the standardised return data. Standardisation reveals greater behavioural noises in the BSE while the same is even up in the NSE market. Whatsoever they are, every decision choice needs strategies and strategies have numerical 'attractions', and those 'attractions' determine their choice probabilities. Based on this spirit, we have empirically explored the magnitudes of the EWA learning parameters. We have showed that intraday traders' adaptive learning decisions are persistent to explore the market microstructure noise.

Since we consider exploring the market returns and the noise thereof, we abort exploration of the parameter $\delta$, the relative weight parameter of the foregone payoffs. The concerned parameter for the foregone payoffs involves a detailed investment strategy. In examining this research gap, the future researches may investigate the use of the EWA parameters for portfolio selection with specific stocks and thereby, they may examine if the presence of behavioural momentum biases and the MMN both influence the choices of intraday traders at behavioural portfolio revisions. A further distant adventure remain unaddressed here is that of exploring the task of quantifying the MMN in the stock markets from the distributional properties of the intraday stocks' returns. A policy recommendation to intraday traders is to judiciously set a time lag length to update their early attraction strength $\mathrm{N}(\mathrm{p})_{\mathrm{t}}$ and revise the experience time horizons accordingly. Market regulators can restrict more frequent activity from 
a single particular trader within a short time interval viz., 5-15 munities so that traders' judicious decisions prevail over impulsive decisions.

\section{Acknowledgements}

The author acknowledges his deep regards and thanks to anonymous reviewers for their insightful comments and thoughtful suggestions on different aspects of the paper.

\section{Declaration of Conflict of Interest}

The author declared no potential conflict of interest with respect to the research, authorship, and publication of this article.

\section{References}

A1t-Sahalia1, Y., \& Yu, J. (2009). High frequency market microstructure noise estimates and liquidity measures. Annals of Applied Statistics, 3(1), 422-457. doi:10.1214/08-AOAS200.

Andersen, T. G., Bollerslev, T., \& Meddahi, N. (2011). Realized volatility forecasting and market microstructure noise. Journal of Econometrics, 160(1), 220-234. doi:10.1016/j.jeconom.2010.03.032

Andersen, T. G., Bollerslev, T., Diebold, F. X., \& Ebens, H. (2001). The distribution of realized stock return volatility. Journal of Financial Economics, 61(1), 43-76. doi:10.1016/S0304-405X(01)00055-1

Andersen, T. G., Cebiroglu, G., \& Hautsch, N. (2017). Volatility, information feedback, and market microstructure noise: A tale of two regimes. Retrieved from https://ssrn.com/abstract=2921097. doi:10.2139/ssrn.2921097

Anderson, E. W., Ghysels, E., \& Juergens, J. L. (2005). Do heterogeneous beliefs matter for asset pricing? The Review of Financial Studies, 18(3), 875-924. doi:10.1093/rfs/hhi026

Aparicio, F. M., \& Estrada, J. (2001). Empirical distributions of stock returns: European securities markets, 1990-1995. European Journal of Finance, 7(1), 121. doi:10.1080/13518470121786

Ardliansyah, R. (2012). Stock market integration and international portfolio diversification between U.S. and ASEAN equity markets. Centre for Economic and Financial Studies, University of Glasgow. Retrieved from https://mpra.ub.uni-muenchen.de/41958/ doi:10.2139/ssrn.2161330

Baker, M., \& Wurgler, J. (2007). Investor sentiment in the stock market. Journal of Economic Perspectives, 21(2), 129-152. doi:10.1257/jep.21.2.129 
Barber, B. M., Odean, T., \& Zhu, N. (2009). Systematic noise. Journal of Financial Markets, 12(4), 547-569. doi:10.1016/j.finmar.2009.03.003

Bloomfield, R., O’Hara, M., \& Saar, G. (2009). How noise trading affects markets: An experimental analysis. The Review of Financial Studies, 22(6), 2275-2302. doi:10.1093/rfs/hhn102

Boswijk, H. P., Hommes, C. H., \& Manzan, S. (2007). Behavioral heterogeneity in stock prices. Journal of Economic Dynamics and Control, 31(1), 1938-1970. doi:10.1016/j.jedc.2007.01.001

Camerer, C., \& Ho, H. T. (1999). Experience-weighted attraction learning in normal form games. Econometrica, 67(4), 827-874. doi:10.1111/1468-0262.00054

Chen, S.-H., \& Du, Y.-R. (2017). Heterogeneity in generalized reinforcement learning and its relation to cognitive ability. Cognitive Systems Research, 42(1), 1-22. doi:10.1016/j.cogsys.2016.11.001

Chin, W. C., \& Lee, M. C. (2018). S\&P500 volatility analysis using high-frequency multipower variation volatility proxies. Empirical Economics, 54(3), 12971318. doi: 10.1007/s00181-017-1345-Z

Chung, Y. P., Johnson, H., \& Schill, M. J. (2006). Asset pricing when returns are nonnormal: Fama-French factors versus higher-order systematic comments. The Journal of Business, 79(2), 923-940. doi:10.1086/499143

Coval, J. D., \& Shumway, T. (2005). Do behavioral biases affect prices? The Journal of Finance, 60(6), 1-34. doi:10.1111/j.1540-6261.2005.00723.x

De Long, J. B., Shleifer, A., Summers, L. H., \& Waldmann, R. J. (1990). Noise trader risk in financial markets. Journal of Political Economy, 98(4), 703-738. doi:10.1086/261703

Diebold, F. X., \& Strasser, G. (2008). On the correlation structure of microstructure noise in theory and practice (PIER Working Paper No. 08-038). doi:10.2139/ssrn.1286143

Dinh, M. T. H. (2017). The returns, risk and liquidity relationship in high frequency trading: Evidence from the Oslo stock market, Research in International Business and Finance, 39(1), 30-40. doi:10.1016/j.ribaf.2016.07.013

Elton, E. J., Gruber, M. J., \& Kleindorfer, P. R. (1975). A closer look at the implications of the stable paretian hypotheses. The Review of Economics and Statistics, 57(2), 231-235. doi:10.2307/1924006

Fama, E. F. (1965). The behaviour of stock market prices. Journal of Business, 38(1), 34-105. doi:10.1086/294743

Firestone, W. A. (1993). Alternative arguments for generalizing from data as applied to qualitative research. Educational Researcher, 22(4), 16-22. $\underline{\text { doi: } 10.2307 / 1177100}$ 
Fung, A. K.-W., Lam, K., \& Lam, K.-M. (2010). Do the prices of stock index futures in Asia overreact to U.S. market returns? Journal of Empirical Finance, 17(3), 428-440. doi:10.1016/j.jempfin.2009.12.006

Gandhi, A., \& Serrano-Padial, R. (2015). Does belief heterogeneity explain asset prices: The case of the longshot bias. The Review of Economic Studies, 82(1), 156-186. doi:10.1093/restud/rdu017

Garcia, R., Renault, E., \& Veredas, D. (2011). Estimation of stable distributions by indirect inference. Journal of Econometrics, 161(2), 325-337. doi:10.1016/j.jeconom.2010.12.007

Ghose, D., \& Kroner, K. F. (1995). The relationship between GARCH and symmetric stable processes: Finding the source of fat tails in financial data. Journal of Empirical Finance, 2(3), 225-251. doi:10.1016/0927-5398(95)00004-e

Gkillas, K., Gupta, R., Lau, C. K. M., \& Suleman, M. T. (2019). Jumps beyond the realms of cricket: India's performance in one day internationals and stock market movements. Journal of Applied Statistics, 1-19. doi:10.1080/02664763.2019.1663157

Gupta, R., \& Yang, J. (2011). Testing weak form efficiency in the Indian capital market. International Research Journal of Finance and Economics, 75(1), 108 119. Retrieved from https://core.ac.uk/download/pdf/143889780.pdf

Hansen, P. R., \& Lunde, A. (2006). Realized variance and market microstructure noise. Journal of Business and Economic Statistics, 24(2), 127-161. doi:10.1198/073500106000000071

He, X. Z. (2012). Recent developments in asset pricing with heterogeneous beliefs and adaptive behaviour of financial markets. G. Bischi, C. Chiarella I. Sushko (Eds.), Global analysis of dynamic models in economics and finance. Berlin, Heidelberg: Springer. doi:10.1007/978-3-642-29503-4_1

Ho, T. H., Lim, N., \& Camerer, C. F. (2006). Modeling the psychology of consumer and firm behavior with behavioral economics. Journal of Marketing Research, 43(3), 307-331. doi:10.1509/jmkr.43.3.307

Jaffe, A. (2010). Cardiac excitability: Impulse, restraint, and "the pulse of the people". in The affective life of the average man: the Victorian novel and the stock-market graph. The Ohio State University Press.

Joseph, A., Turner, C., \& Jeremiah, R. (2016). Comparative analyses of stock returns properties and predictability. Procedia Computer Science, 95, 272-280. doi:10.1016/j.procs.2016.09.333

Kasa, K., Walker, T. B., \& Whiteman, C. H. (2013). Heterogeneous beliefs and tests of present value models, Review of Economic Studies, 81(3), 1137-1163. $\underline{\text { doi:10.1093/restud/rdt051 }}$ 
Kim, D., \& Kon, S. J. (1994). Alternative models for the conditional heteroscedasticity of stock returns. Journal of Business, 67(4), 563-598. doi: $10.1086 / 296647$

Kumari, J., \& Mahakud, J. (2015). Does investor sentiment predict the asset volatility? Evidence from emerging stock market India. Journal of Behavioral and Experimental Finance, 8(1), 25-39. doi:10.1016/j.jbef.2015.10.001

Kumari, J., \& Mahakud, J. (2016). Investor sentiment and stock market volatility: Evidence from India. Journal of Asia-Pacific Business, 17(2), 173-202. doi:10.1080/10599231.2016.1166024

Kyle, A. (1985). Continuous auctions and insider trading. Econometrica, 53(6), 1315-1336. doi:10.2307/1913210

Luckner, S., Schröder, J., Slamka, C., Skiera, B., Spann, M., Weinhardt, C., ... Franke, M. (2011). Prediction markets: Fundamentals, designs, and applications. Springer Science and Business Media.

Mandelbrot, B. (1962). A class of long-tailed probability distributions and the empirical distribution of city sizes, Research note, Thomas J. Watson Research Center: Yorktown Heights, N.Y.

Mandelbrot, B. (1965). A class of long-tailed probability distributions and the empirical distribution of city sizes. In F. Massarik \& P. Ratoosh (Eds.), Mathematical explorations in behavioral sciences (pp. 272-274). Homewood, Il: Richard D. Irwin.

Mandelbrot, B., \& Hudson, R. L. (2007). The misbehavior of markets: A fractal view of financial turbulence. Basic books.

Martin, N. (2012). Noise, neoliberalism and Iain Sinclair (Unpublished Doctoral dissertation). Universiteit van Amsterdam. Retrieved from https://hdl.handle.net/11245/1.367659

McCulloch, J. H. (1996). Financial applications of stable distributions. In G. S. Maddala, \& C. R. Rao (Eds.), Statistical methods in finance Handbook of statistics (Vol 14) (pp. 393-425). Elsevier.. doi:10.1016/S0169-7161(96)14015$\underline{3}$

Moseki, K. K., Rao, K. S. M., \& McMillan, D. (2017). Analysing stock market data - Market sentiment approach and its measures. Cogent Economics and Finance, 5(1), 1-15. doi:10.1080/23322039.2017.1367147

Pan, D., Shi, J., Wu, F., \& Zhang, B. (2015). Investor heterogeneity and commonality in stock return and liquidity. Economic Systems, 39(3), 458473.doi:10.1016/j.ecosys.2015.07.001

Pearson, K. (1905). Das Fehlergesetz und seine Verallgemeinerungen durch Fechner und Pearson. A Rejoinder. Biometrika, 4(1), 169-212. doi:10.1093/biomet/4.1$\underline{2.169}$ 
Peters, E. E. (1994). Fractal market analysis: Applying chaos theory to investment and economics (Vol. 24). John Wiley \& Sons, New York.

Peters, E. E. (1996). Chaos and order in the capital markets: A new view of cycles, prices, and market volatility. John Wiley \& Sons.

Poshakwale, S. (1996). Evidence on weak form efficiency and day of the week effect in the Indian stock market. Finance India, 10(3), 605-616.

Rao, T., \& Srivastava, S. (2012). Analyzing stock market movements using Twitter sentiment analysis. ASONAM '12 Proceedings of the 2012 International Conference on Advances in Social Networks Analysis and Mining, pp. 119-123, IEEE Computer Society Washington, DC, USA. Retrieved from https://dl.acm.org/citation.cfm?id=2456719.2456923.

Richardson, M., \& Smith, T. (1993). A test for multivariate normality in stock returns. Journal of Business, 66(2), 295-321. doi:10.1086/296605

Runkel, P. J., \& McGrath, E. J. (1972). Research on human behavior: A systematic guide to method. New York: Holt, Rinehart and Winston, Inc

Shiller, R. J. (2015). Irrational exuberance: Revised and expanded third edition. Princeton University Press.

Shleifer, A., \& Vishny, R. W. (1997). The limits of arbitrage. Journal of Finance, 52(1), 35-55. doi:10.1111/j.1540-6261.1997.tb03807.x

Sinha, P. C. (2015a). Stocks' pricing dynamics and behavioral finance: A review. Management Science Letters, 5(9), 797-820. doi: 10.5267/j.ms1.2015.7.003

Sinha, P. C. (2015b). Dynamics of noise traders' risk in the NSE and BSE markets. International Journal of Financial Management, 5(4), 36-64. doi:10.21863/ijfm/2015.5.4.021

Sinha, P. C. (2016a). Herd behavior: How decisive is the noise in the NSE and BSE stock markets? International Journal of Financial Management, 6(1), 1-16. doi:10.21863/ijfm/2016.6.1.023

Sinha, P. C. (2016b). Systematic risk and liquidity risk in the NSE market: A critique on $\mathrm{R}^{2}$. The IUP Journal of Applied Finance, 22(3), 5-40.

Sinha, P. C. (2018). Investors' trading biases and information: Experimental analysis. International Journal of Exclusive Management Research, [Special Issue], 2018, 35-56.

Steinbacher, M. (2012). Simulating portfolios by using models of social networks (Unpublished doctoral dissertation) Retrieved from http://www.cek.ef.uni1j.si/doktor/steinbacher.pdf

Subbotin, A. (2010). Multiple investment horizons and stock price dynamics (Unpublished doctoral dissertation). Université Panthéon-Sorbonne, Paris.

Summa, J. F. (2004). Trading against the crowd: Profiting from fear and greed in stock, futures and options markets (Vol. 208). John Wiley \& Sons. 
Trippi, R., Chorafas, D. N., \& Sekiguchi, M. (1994). Chaos theory in the financial markets. McGraw-Hill, Inc.

Tuyon, J., Ahmad, Z., \& Matahir, H. (2016). The roles of investor sentiment in Malaysian stock market. Asian Academy of Management Journal of Accounting and Finance, 12(Suppl.1), 43-75. doi:10.21315/aamjaf2016.12.S1.3

Tziralis, G., \& Tatsiopoulos, I. (2007). Prediction markets: An information aggregation perspective to the forecasting problem. World Review of Entrepreneurship, Management and Sustainable Development, 3(3), 251-259. doi:10.1504/WREMSD.2007.014044

Westfall, P. H. (2014). Kurtosis as peakedness, 1905-2014. R.I.P. The American Statistician, 68(3), 191-195. doi:10.1080/00031305.2014.917055

Wolfers, J., \& Zitzewitz, E. (2004). Prediction markets. Journal of Economic Perspectives, 18(2), 107-126. doi:10.1257/0895330041371321

Xu, Y., Liu, Z., Zhao, J., \& Su, C. (2017). Weibo sentiments and stock return: A timefrequency view. PLoS ONE, 12(7), 1-21.edoi:10.1371/journal.pone.0180723

Yalamova, R., \& McKelvey, B. (2011). Explaining what leads up to stock market crashes: A phase transition model and scalability dynamics. Journal of Behavioral Finance, 12(3), 169-182. doi:10.1080/15427560.2011.602484.

Ye, M., \& Li, G. (2017). Internet big data and capital markets: A literature review. Financial Innovation , 3(6), 1-18. doi:10.1186/s40854-017-0056-y

Yoon, S. M., \& Kang, S. H. (2008). Non-periodic cycles and long memory property in the Korean stock market. The Journal of the Korean Economy, 9(3), 403-424.

\section{Appendix 1: Intraday Data Description for the NSE Nifty Index and the BSE Sensex Index}

\begin{tabular}{|c|c|}
\hline $\begin{array}{l}\text { Months } \\
\text { (No. of Days) }\end{array}$ & Dates (With an average 375 Size of Data) \\
\hline $\begin{array}{l}\text { July, } 2016 \\
(13)\end{array}$ & $\begin{array}{l}13^{\text {th }}, 14^{\text {th }}, 15^{\text {th }}, 18^{\text {th }}, 19^{\text {th }}, 20^{\text {th }}, 21 \text { th }, 22 \text { th }, 25^{\text {th }}, 26^{\text {th }}, 27^{\text {th }}, 28^{\text {th }} \text {, and } 29^{\text {th }} \\
\text { July, } 2016\end{array}$ \\
\hline $\begin{array}{l}\text { August, } 2016 \\
(21)\end{array}$ & $\begin{array}{l}1^{\text {st }}, 2^{\text {nd }}, 3^{\text {td }}, 4^{\text {th }}, 5^{\text {th }}, 8^{\text {th }}, 9^{\text {th }}, 10^{\text {th }}, 11^{\text {th }}, 12^{\text {th }}, 16^{\text {th }}, 17^{\text {th }}, 19^{\text {th }}, 22 \text { th }, 23 \text { th }, 24^{\text {th }}, \\
25^{\text {th }}, 26^{\text {th }}, 29^{\text {th }}, 30^{\text {th }} \text {, and } 31^{\text {st }} \text { August, } 2016\end{array}$ \\
\hline $\begin{array}{l}\text { September, } 2016 \\
(18)\end{array}$ & $\begin{array}{l}1^{\text {st }}, 2^{\text {nd }}, 5^{\text {th }}, 6^{\text {th }}, 7^{\text {th }}, 8^{\text {th }}, 9^{\text {th }}, 12^{\text {th }}, 14^{\text {th }}, 16^{\text {th }}, 19^{\text {th }}, 20^{\text {th }}, 21^{\text {st }}, 23 \text { th }, 27^{\text {th }}, 28^{\text {th }}, \\
29^{\text {th }} \text {, and } 30^{\text {th }} \text { September } 2016\end{array}$ \\
\hline $\begin{array}{l}\text { October, } 2016 \\
\text { (6) }\end{array}$ & $3^{\text {rd }}, 4^{\text {th }}, 6^{\text {th }}, 7^{\text {th }}, 21^{\text {st }}, 27^{\text {th }}$ October, 2016 \\
\hline $\begin{array}{l}\text { November, } 2016 \\
\text { (3) }\end{array}$ & $1^{\text {st }}, 3^{\text {rd }}$, and $4^{\text {th }}$ November, 2016 \\
\hline $\begin{array}{l}\text { December, } 2016 \\
(14)\end{array}$ & $\begin{array}{l}1^{\text {st }}, 2^{\text {nd }}, 6^{\text {th }}, 7^{\text {th }}, 8^{\text {th }}, 9^{\text {th }}, 12^{\text {th }}, 13^{\text {th }}, 14^{\text {th }}, 15^{\text {th }}, 16^{\text {th }}, 19^{\text {th }}, 20^{\text {th }}, \text { and } 23^{\text {rd }} \\
\text { December, } 2016\end{array}$ \\
\hline
\end{tabular}




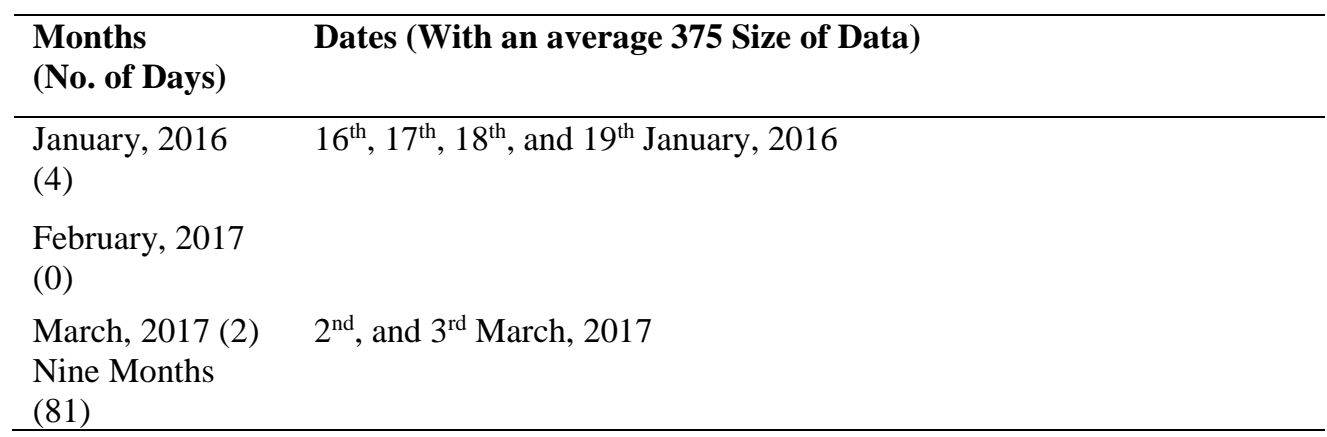

\section{Appendix 2: Variable Definitions, Data Transformation, and Steps for Parameter Values}

1. Log of Index Relative $\left(\mathrm{LIR}_{\mathrm{t}}\right)=\mathrm{LN}\left(\mathrm{OI}_{\mathrm{t}} / \mathrm{OI}_{\mathrm{t}-1}\right)$, "OII

2. Mean Return of Log Index Relative $\left(M R \_L I R t\right)=$ Average $\left(\operatorname{LIR}_{t=-1}: \operatorname{LIR}_{t}=-30\right)$

3. Standardised Return of Log Relatives $\left(\operatorname{SR}_{-} \operatorname{LIR}_{t}\right)=\operatorname{LIR}_{t} / \operatorname{VLIR}_{t}(t=-1,-2, \ldots-30)$

4. Mean Conditioned Standardised Return of Log Relatives $\left(M_{C}\right.$ SS_LIR $\left.{ }_{t}\right)=$ MR_LIR $t$ VLIR $_{\mathrm{t}(\mathrm{t}=-1, . .-30)}$

5. Steps for determining the three EWA Parameter Values:

Stage-1 (Base data generation):

1. Calculate the return $\left(R_{t}\right)$ variables, variance variables, skewness variables and kurtosis variables for the return definitions of $\mathrm{LIR}_{\mathrm{t}}, \mathrm{MR}_{-} \mathrm{LIR}_{\mathrm{t}}, \mathrm{SR}_{-} \mathrm{LIR}_{\mathrm{t}}$, and MCSR_LIR

2. Let a time frame $\left(T_{t=t-100, t}\right)$ to view the early attraction window $A_{i}{ }^{j}(p)$ of an $i-t h$ trader for his $\mathrm{j}$-th asset at a tracing point $\mathrm{p}$ being zero at time interval $\mathrm{T}_{-100}$ and $\mathrm{T}_{0}$ and progressive thereafter

3. Set motivation objective to trace early attraction window $\mathrm{A}_{\mathrm{i}} \mathrm{j}(0)$ like target price or index ( or return or variance or skewness or kurtosis etc.) for decision choices

Stage-2 (Initial attraction data):

4. Trace initial attraction window $\mathrm{A}_{\mathrm{i}} \mathrm{j}(\mathrm{p}=0)$ of an $\mathrm{i}$-th trader for his $\mathrm{j}$-th asset at a tracing point $\mathrm{p}$ being zero and between the time interval $\mathrm{T}_{-100}$ and $\mathrm{T}_{0}$

5. Place binary unity if the relevant attraction window has a favourable value or zero for else on a continuous time basis and find cumulative of the numerals over $\mathrm{T}_{-100}$ and $\mathrm{T}_{0}$ and divided by the number of tracing points i.e., all cases of 1-s and zero-s

6. Acknowledge trader's dynamic initial attraction window: Acknowledge trader's cumulative initial attraction window in a dynamic time frame at $A_{i}{ }^{j}(p)_{t}$ at the time interval $\mathrm{T}_{\mathrm{t}-100}$ and $\mathrm{T}_{\mathrm{t}}$

7. Calculate decay of initial attraction: From cumulative weight of early attraction, find the series of decay of initial attraction being defined as the difference over two consecutive values 
Stage-3 (Experience strength data):

8. Acknowledge trader's current attraction window: For possible buy or sell etc., over time interval of $T_{t}$ to $T_{t+100}$, acknowledge trader's current attraction numerals in unity or zero. Place unity if relevant attraction window has a favourable value or zero for else on a continuous time basis

9. Calculate weight for attraction strength: Being the cumulative of the attraction values of 1-s and zero-s divided by the total number of tracing points i.e., all cases of 1-s and zero-s and

10. Calculate decay in attraction strength: From cumulative weight of attraction strength, find the series of decay of attraction strength being defined as the difference over two consecutive values

\section{Appendix 3: Graphs for AD Normality Test for the Different Variable defining Market Return, Variance, Skewness, and Kurtosis at the BSE Sensex Data}
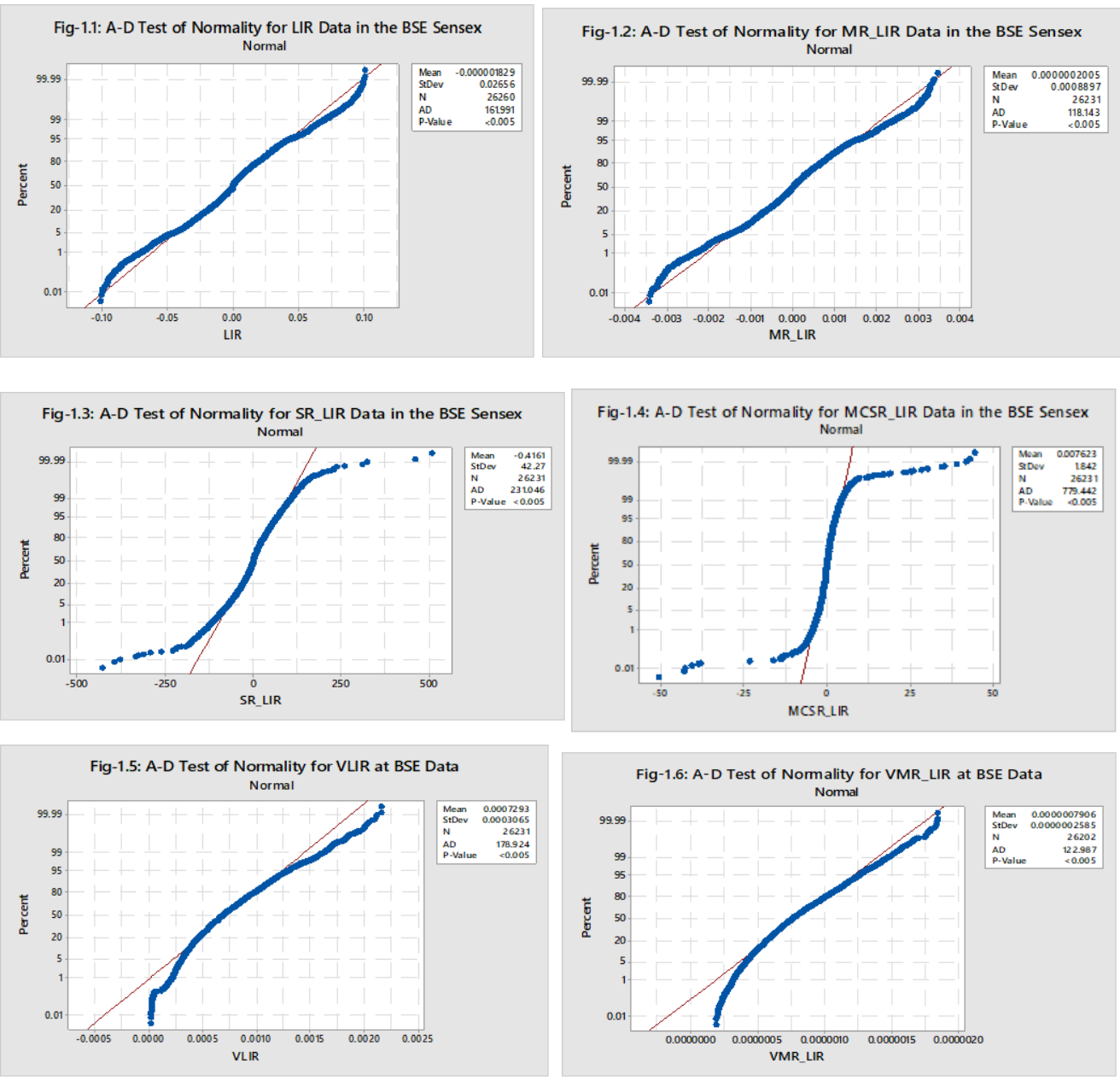

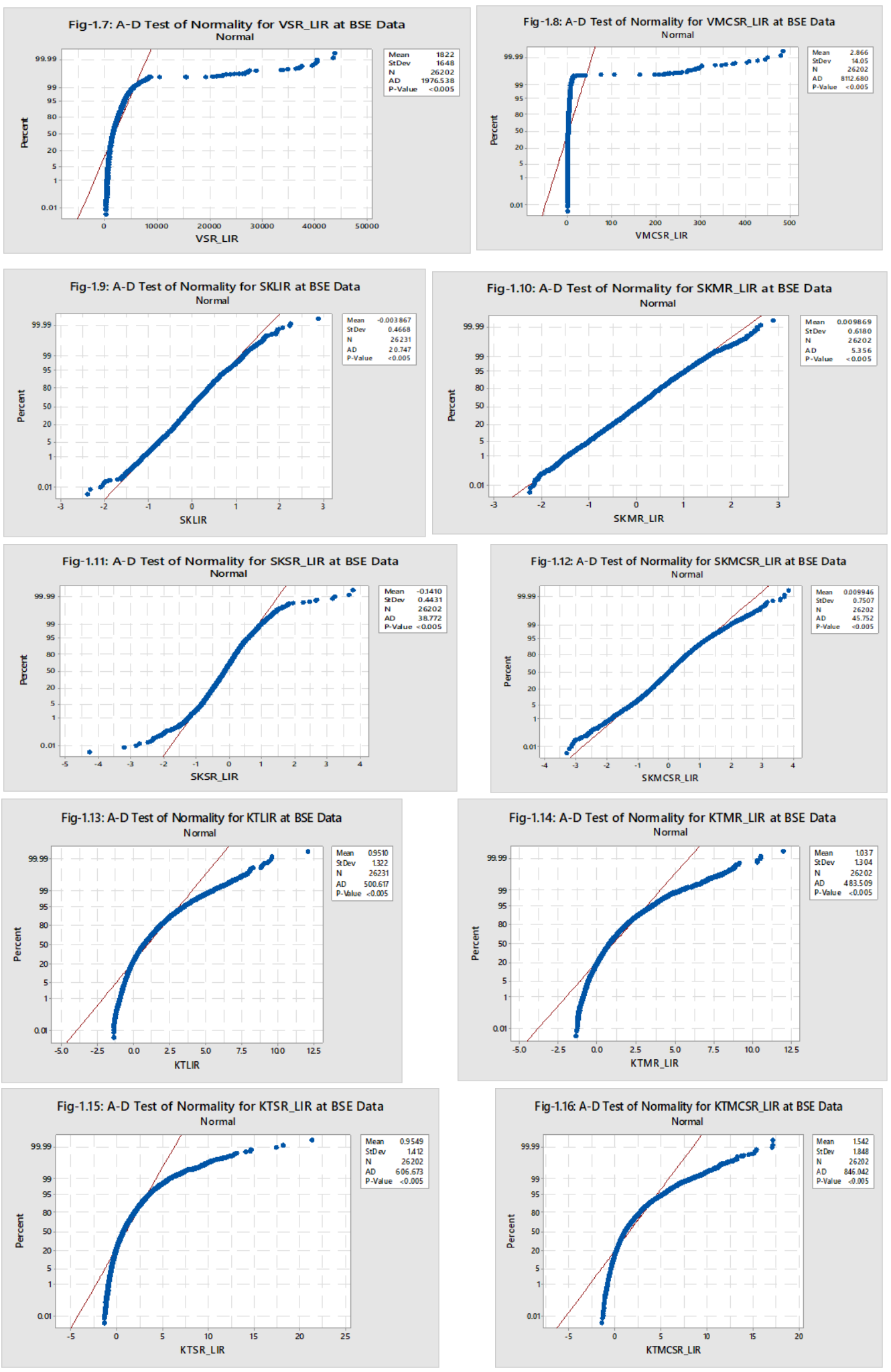
Appendix 4: Graphs for A-D Normality Test for the Different Variable defining Market Return, Variance, Skewness, and Kurtosis at the NSE Nifty Data
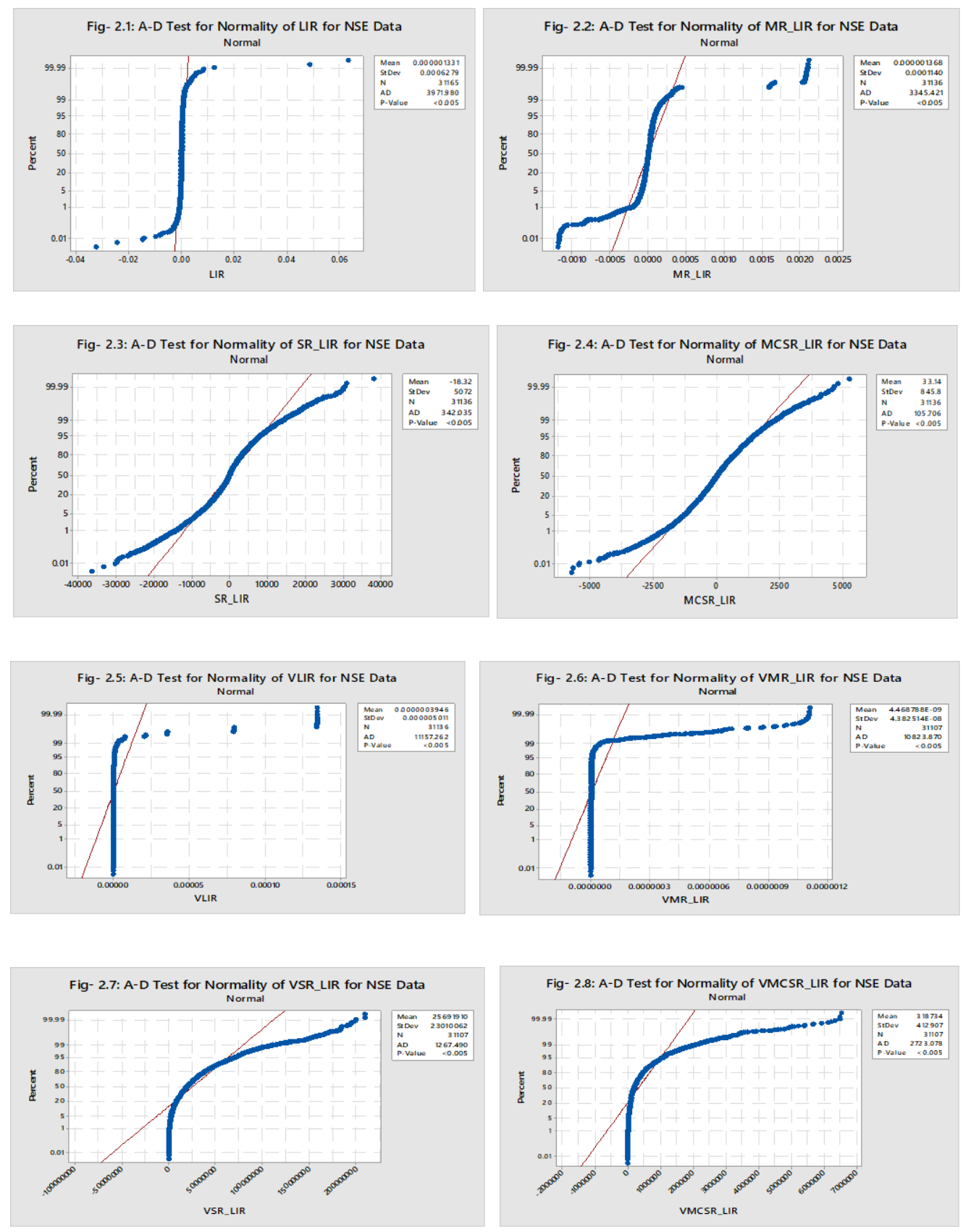

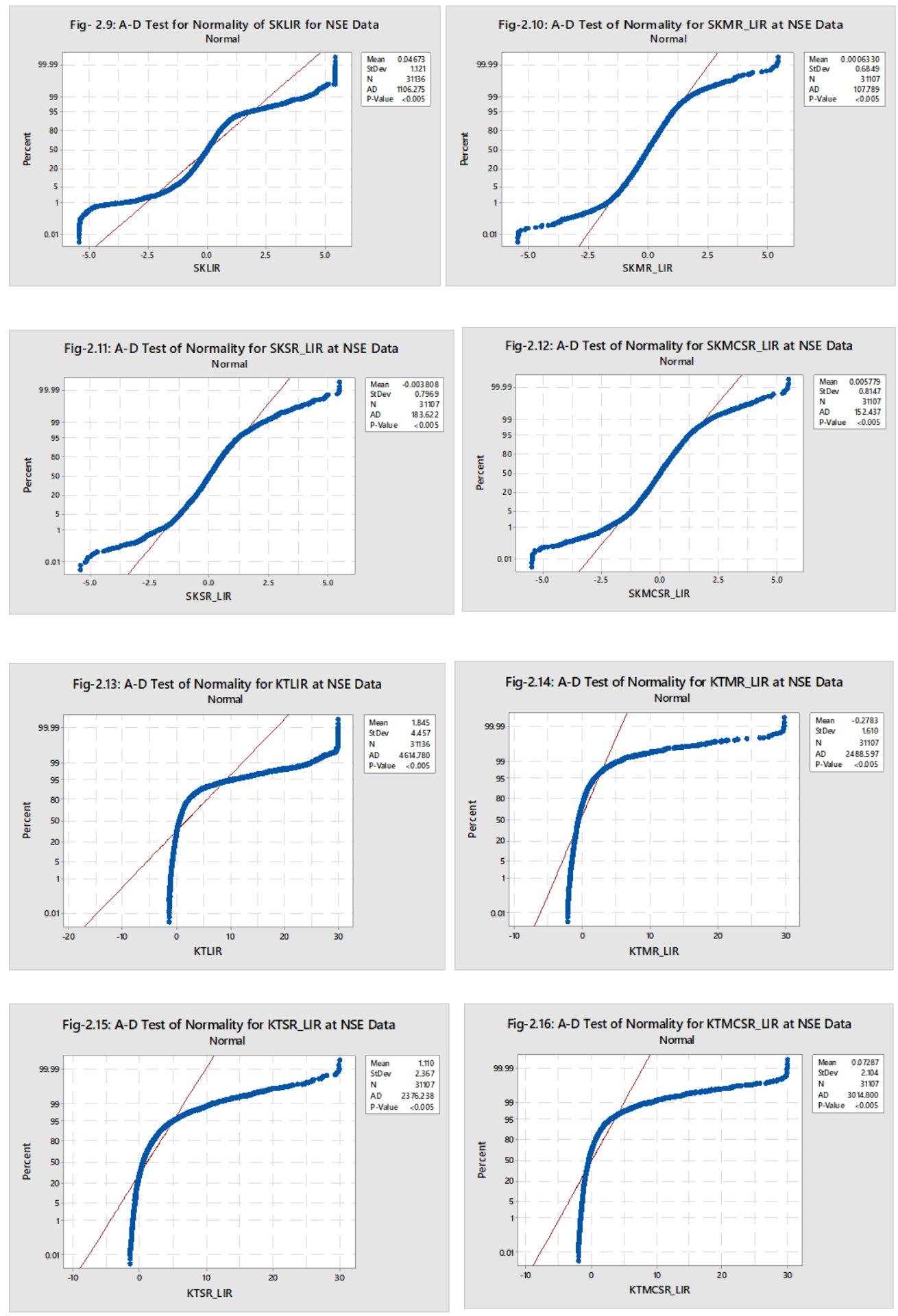